\title{
CRÓNICA CONSTITUCIONAL DEL AÑO 2004
}

\author{
POR \\ MIGUEL ANGEL PRESNO LINERA \\ Profesor Titular de Derecho Constitucional \\ Universidad de Oviedo
}

\begin{abstract}
En esta Crónica se realiza una presentación de carácter temático y no exclusivamente cronológica, por entender que así se puede ofrecer una panóramica más completa de los sucesos acaecidos, muchos de los cuales no se han concretado en un único momento temporal, sino que han tenido un desarrollo progresivo a lo largo de los doce meses examinados 0 , incluso, se extienden a años sucesivos. Como resulta obvio, dentro de cada sección o apartado sí se realiza una ordenación temporal. Los grandes bloques temáticos se refieren a los partidos políticos y los procesos electorales, la Unión Europea, los órganos constitucionales y autonómicos, la organización territorial del Estado, los derechos, deberes y libertades de los ciudadanos y, por último, las relaciones internacionales.
\end{abstract}

\section{PARTIDOS POLÍTICOS Y PROCESOS ELECTORALES}

Respecto al funcionamiento interno de las formaciones políticas cabe recordar que en el 36 Congreso Federal del Partido Socialista Obrero Español (2 al 4 de julio) fue reelegido José Luis Rodríguez Zapatero como Secretario General; en el XV Congreso del Partido Popular ( 1 al 3 de octubre) fue elegido Presidente Mariano Rajoy; en este Congreso también fueron modificados los Estatutos del partido. Gaspar Llamazares fue reelegido como Coordinador General de Izquierda Unida (12 de diciembre). 
A propósito de los procesos electorales, y en lo que afecta a las reformas legislativas, han de mencionarse la Ley Foral 4/2004, de 2 de junio, de modificación del artículo 21 de la Ley Foral 16/1986, de 17 de noviembre, reguladora de las elecciones al Parlamento de Navarra. A partir de su entrada en vigor, "las Administraciones públicas de Navarra no podrán realizar inauguraciones, ni colocación de primeras piedras durante los treinta días naturales anteriores al día en que se celebren las elecciones" (BON n. ${ }^{\circ} 70$, de 11 de junio; BOE n. ${ }^{\circ} 170$, de 15 julio), y la Ley $12 / 2004$, de 7 de diciembre, por la que se modifica la Ley 8/1985, de 13 de agosto, de elecciones al Parlamento de Galicia, para trasladar el escrutinio general al octavo día siguiente al de la votación (DOG n. ${ }^{\circ}$ 243, de 16 de diciembre; BOE n. ${ }^{\circ}$, de 8 de enero de 2005).

Respecto a las convocatorias electorales a lo largo del año 2004 han de citarse, en primer lugar, las elecciones generales celebradas el día 14 de marzo con una participación del 77,21\%.

En los comicios al Congreso de los Diputados, el Partido Socialista Obrero Español consiguió 11.026 .163 votos $(43,27 \%)$ y 164 escaños; el Partido Popular obtuvo 9.635 .491 votos $(37,81 \%)$ y 146 escaños; Convergència i Unió 835.471 (3,28\%) y 10 escaños; Izquierda Unida 801.821 $(3,15 \%)$ y 2 escaños; Esquerra Republicana de Catalunya 652.186 $(2,56 \%)$ y 8 escaños; el Partido Nacionalista Vasco $420.980(1,65 \%)$ y 7 escaños; Coalición Canaria 235.221 (0,92\%) y 3 escaños; Iniciativa per Catalunya Verds-Esquerda Unida i Alternativa $234.790(0,92 \%)$ y 2 escaños; el Bloque Nacionalista Galego 208.682 (0,82\%) y 2 escaños; Unión del Pueblo Navarro-PP $127.653(0,50 \%)$ y 2 escaños; Coalición Esquerra Unida Pais Valencia-Izquierda Republicana (ENTESA) 123.611 votos $(0,49 \%)$ y 1 escaño; Chunta Aragonesista $94.252(0,37 \%)$ y 1 escaño; Eusko Alkartasuna $80.905(0,32 \%)$ y 1 escaño, y Nafarroa Bai 61.045 votos $(0,24 \%)$ y 1 escaño.

En las elecciones al Senado el Partido Popular obtuvo 102 escaños; el Partido Socialista Obrero Español 81; Entesa Catalana de Progrés 12; el Partido Nacionalista Vasco 6; Convergència i Unió 4; Coalición Canaria 3.

El 14 de marzo también se celebraron las elecciones al Parlamento de Andalucía: el Partido Socialista Obrero Español de Andalucía consiguió 2.241 .480 votos $(50,27 \%)$ y 61 escaños; el Partido Popular obtuvo 1.417 .496 votos $(31,79 \%)$ y 37 escaños; Izquierda Unida 335.035 (7,51\%) y 6 escaños, y el Partido Andalucista $275.940(6,19 \%)$ y 5 escaños. La participación fue del $75,85 \%$.

El 13 de junio se celebraron las elecciones al Parlamento Europeo: el 
PSOE obtuvo 25 escaños, el PP 23, la coalición Galeusca 3, IU-ICVEUiA 2 y la coalición Europa de los Pueblos 1; la participación fue del $45,94 \%$.

Antes de la celebración de las elecciones europeas se resolvió el recurso de amparo electoral interpuesto por la candidatura de la agrupación de electores Herritarren Zerenda contra las Sentencias de la Sala Especial del Tribunal Supremo del artículo 61 de la Ley Orgánica del Poder Judicial, de 21 de mayo de 2004. Esta Sala consideró que existía una vinculación de sus promotores y de la mitad de los integrantes de la candidatura con la formación ilegalizada Batasuna.

Esta candidatura presentó dos recursos de amparo electoral de acuerdo con las previsiones del apartado 5 del artículo 49 LOREG. EI Tribunal Constitucional rechazó los recursos en la STC 99/2004, de 27 de mayo, reproduciendo la jurisprudencia presente en la STC 85/2003, de 8 de mayo, sobre la perentoriedad de los recursos electorales y el rechazo razonado de pruebas o de su impugnación; sobre los datos personales de los candidatos y sobre las agrupaciones electorales que de hecho continúan o suceden en la actividad de un partido político ilegal. Se emitió un Voto particular concurrente.

\section{UNIÓN EUROPEA}

En el ámbito de la Unión Europea deben recordarse los siguientes eventos: el 1 de enero Irlanda asumió la Presidencia del Consejo de la Unión Europea; el 1 de mayo entró en vigor el Tratado de Adhesión y se produjo la mayor ampliación de la Unión Europea, con diez nuevos países: Chipre, la República Checa, Estonia, Hungría, Letonia, Lituania, Malta, Polonia, la República Eslovaca y Eslovenia; el 5 mayo el Parlamento Europeo celebró una votación para nombrar a los diez nuevos Comisarios y el Consejo de Ministros los nombró oficialmente.

Como se acaba de indicar, el 13 de junio se celebraron las elecciones al Parlamento Europeo; los resultados en España fueron los siguientes: el PSOE obtuvo 25 escaños, el PP 23, la coalición Galeusca 3, IU-ICV-EUiA 2 y la coalición Europa de los Pueblos 1; la participación fue del $45,94 \%$.

En el Consejo Europeo celebrado en Bruselas los días 17 y 18 de junio se desbloqueó la negociación sobre el Tratado por el que se establece una Constitución para Europa; de entrar en vigor, en la «Europa a 27 ", la mayoría cualificada estará en el $55 \%$ de los votos que representen el $65 \%$ de la población 
El 29 de junio se celebró la sesión n. ${ }^{\circ} 2595$ del Consejo de Jefes de Estado o de Gobierno en Bruselas, en la que se nombró a José Manuel Durão Barroso Presidente de la Comisión, a Javier Solana Secretario General del Consejo y Alto Representante de la PESC y a Pierre de Boissieu Secretario General Adjunto.

EI 1 de Julio, los Países Bajos asumieron la Presidencia del Consejo de la Unión Europea.

El 20 de ese mes, el recién elegido Parlamento Europeo nombró como Presidente a Josep Borrell. El 22, el Parlamento Europeo aprobó el nombramiento de José Manuel Durão Barroso como Presidente de la Comisión; éste presentó el 12 de agosto la propuesta de distribución de las 24 carteras; del 27 de septiembre al 8 de octubre, las comisiones especializadas del Parlamento Europeo celebraron una serie de audiencias con los candidatos a Comisarios a fin de preparar el voto de aprobación para el nuevo Colegio de Comisarios en su conjunto; el 26 de octubre, Durão Barroso retiró la propuesta; finalmente, el 18 de noviembre, el Parlamento Europeo aprobó la nueva Comisión por 449 votos a favor, 149 en contra y 82 abstenciones.

El 29 de octubre, los Jefes de Estado y de Gobierno y los Ministros de Asuntos Exteriores de la UE firmaron en Roma el Tratado por el que se establece una Constitución para Europa. Los países de la Unión disponen de un plazo de dos años para ratificar el Tratado.

Por lo que se refiere al proceso de ratificación del Tratado en España, deben señalarse los siguientes hitos: el 5 de noviembre, el Consejo de Ministros acordó hacer uso del artículo 95.2 de la Constitución para requerir al Tribunal Constitucional que se pronunciase acerca de si esa ratificación exigía una previa revisión de la Constitución de 1978. El Tribunal Constitucional, en su Declaración 1/2004, de 13 de diciembre, respondió "que no existe contradicción entre la Constitución española y el artículo I-6 del Tratado por el que se establece una Constitución para Europa, firmado en Roma el 29 de octubre de 2004"; "que no existe contradicción entre la Constitución española y los arts. II-111 y II112 de dicho Tratado" y "que el art. 93 de la Constitución española es suficiente para la prestación del consentimiento del Estado al Tratado referido"; se formularon tres Votos particulares discrepantes.

Tras la Declaración del Tribunal Constitucional, el Gobierno, una vez obtenida la autorización del Congreso de los Diputados, aprobó el Real Decreto 5/2005, de 14 de enero (BOE n. ${ }^{\circ} 13$, de 15 de enero), "por el que se somete a referéndum consultivo de la Nación la decisión política de ratificar el Tratado por el que se establece una Constitución 
para Europa». La fecha de la consulta fue el 20 de febrero y se produjeron los siguientes resultados: 10.804 .464 votos favorables a la ratificación (76,73\%); 2.428 .409 contrarios (17,24\%); 849.03 en blanco $(6,03 \%)$ y 122.697 nulos $(0,86 \%)$; la participación fue del $42,32 \%$.

Por lo que respecta a la trasposición de Directivas comunitarias al ordenamiento jurídico español hay que señalar que, en el momento de concluir estas líneas (9 de marzo de 2005), están pendientes un total de 122 (31 con plazo vencido y 91 con plazo no vencido).

\section{3. ÓRGANOS CONSTITUCIONALES Y AUTONÓMICOS}

En lo relativo a las Cortes Generales ha de comenzarse recordando la sesión constitutiva de las Cámaras el día 2 de abril y el inicio de la VIII Legislatura; en el Congreso de los Diputados, se procedió a la elección del Presidente de la Cámara, resultando elegido Manuel Marín con 202 votos a favor; 2 a favor de José Blanco; 142 en blanco y tres nulos. Además, resultaron elegidos los cuatro Vicepresidentes (Carme Chacón, Jordi Vilajoana, Gabriel Cisneros e Ignacio Gil Lázaro) y los cuatro Secretarios (María Jesús Sainz, Celia Villalobos, Javier Barrero e Isaura Navarro).

En el Senado, en la votación para Presidente se produjeron los siguientes resultados: Rosa Vindel 123 votos y Javier Rojo 128 votos, por lo que resultó proclamado Presidente Javier Rojo. Como Vicepresidentes resultaron elegidos Juan José Lucas e Isidre Molas y como Secretarios Iñaqui Anasagasti, Jordi Casas, Damián Caneda y José Manuel Barquero.

Ha de reseñarse que en el Congreso de los Diputados se constituyó, el 27 de mayo, la Comisión de Investigación sobre el 11 de marzo de 2004; para su presidencia resultó elegido el Diputado Paulino Rivero (Diario de Sesiones, Comisiones de Investigación, VIII Legislatura n. ${ }^{\circ} 1$ ); los trabajos se han desarrollado a lo largo del año 2004 y prosiguen en los primeros meses de 2005.

Por lo que respecta a los Reglamentos de las Cámaras, ambos fueron modificados.

El del Congreso en su artículo 46.1, que ahora dispone: "Son Comisiones Permanentes Legislativas las siguientes: 1.a Constitucional. 2.a Asuntos Exteriores. 3.a Justicia. 4.a Interior. 5.a Defensa. 6.a Economía y Hacienda. 7.a Presupuestos. 8.a Fomento y Vivienda. 9.a Educación y Ciencia. 10.a Trabajo y Asuntos Sociales. 11.a Industria, Turismo y Comercio. 12.a Agricultura, Pesca y Alimentación. 13.a Administraciones 
Públicas. 14.a Cultura. 15.a Sanidad y Consumo. 16.a Medio Ambiente» (BOE n. ${ }^{\circ} 108$, de 4 de mayo).

El Reglamento del Senado ha sido modificado en dos ocasiones; en la primera se cambiaron los apartados 2 y 3 del artículo 49, quedando redactados en los siguientes términos: "2. Serán Comisiones no Legislativas aquellas que con tal carácter deban constituirse en virtud de una disposición legal, y las siguientes: Reglamento. Incompatibilidades. Suplicatorios. Peticiones. Asuntos Iberoamericanos. De la Sociedad de la Información y del Conocimiento. Nombramientos.". "3. Serán Comisiones Legislativas la Comisión General de las Comunidades Autónomas y las siguientes: Constitucional. Asuntos Exteriores y Cooperación. Justicia. Defensa. Economía y Hacienda. Presupuestos. Interior. Fomento y Vivienda. Educación y Ciencia. Trabajo y Asuntos Sociales. Industria, Turismo y Comercio. Agricultura, Pesca y Alimentación. Administraciones Públicas. Cultura. Sanidad y Consumo. Medio Ambiente. Entidades Locales." (BOE n. ${ }^{\circ} 123$, de 21 de mayo).

En la segunda ocasión se modificaron los artículos 20 y 67: «1. El contenido del párrafo único del artículo 20 pasa a ser apartado 1. 2. Se introduce un nuevo apartado 2 en el artículo 20, con el siguiente contenido: "2. Para el mejor cumplimiento de sus funciones parlamentarias, los Senadores, previo conocimiento del respectivo Grupo Parlamentario, tendrán la facultad de recabar de las Administraciones Públicas los datos, informes o documentos que obren en poder de éstas. La solicitud se dirigirá, en todo caso, por conducto de la Presidencia del Senado y la Administración requerida deberá facilitar la documentación solicitada o manifestar al Presidente del Senado, en plazo no superior a treinta días y para su más conveniente traslado al solicitante, las razones fundadas en Derecho que lo impidan".

El artículo 67 del Reglamento queda redactado en los siguientes términos: "Las Comisiones podrán realizar encuestas o estudios en cuestiones de su competencia, siempre que no esté ya constituida una Comisión de Investigación o Especial, encargando a varios de sus miembros que realicen una información. Además, podrán recabar, a través del Presidente del Senado, la información y ayuda que necesiten del Gobierno y de sus Departamentos y de cualesquiera autoridades del Estado y de las Comunidades Autónomas, así como la documentación necesaria cuando lo solicite un tercio de los miembros de la Comisión, siendo aplicable lo establecido en el apartado 2 del artículo 20. Asimismo, podrán solicitar la presencia de otras personas para ser informadas sobre cuestiones de su competencia." (BOE n. ${ }^{\circ} 303$, de 17 de diciembre).

También ha de recordarse la Resolución de las Mesas del Congreso de los Diputados y del Senado, reunidas en sesión conjunta, de 20 de mayo de 2004, sobre composición de las Comisiones Mixtas Congreso-Senado.

De acuerdo con esta Resolución, las Comisiones Mixtas se compondrán de 42 miembros designados por los Grupos Parlamentarios de 
acuerdo con la siguiente distribución: Grupo Popular: 9 Diputados y 9 Senadores; Grupo Socialista: 11 Diputados y 6 Senadores; Grupo Catalán (CiU)/Grupo Parlamentario Catalán en el Senado de Convergència i Unió: 1 Diputado o 1 Senador; Grupo Parlamentario Entesa Catalana de Progrés: 1 Senador; Grupo Vasco (EAJ-PNV)/Grupo Parlamentario de Senadores Nacionalistas Vascos: 1 Diputado o 1 Senador; Grupo de Esquerra Republicana (ERC): 1 Diputado; Grupo de Izquierda Verde-Izquierda Unida-Iniciativa per Catalunya Verds (IV-IU-ICV): 1 Diputado; Grupo de Coalición Canaria/Grupo Parlamentario de Senadores de Coalición Canaria: 1 Diputado o 1 Senador; Grupo Mixto: 1 Diputado o 1 Senador.

En las votaciones en las Comisiones Mixtas se entenderá que no existe empate cuando la igualdad de votos, siendo idéntico el sentido en el que hubieren votado todos los miembros de la Comisión pertenecientes a un mismo Grupo Parlamentario, pudiera dirimirse ponderando el número de votos con que cada Grupo cuente (BOCG-Cortes Generales, Serie $A, n .^{\circ} 2$, de 25 de mayo de 2004).

En el Congreso de los Diputados se aprobó la Resolución de la Presidencia del Congreso sobre secretos oficiales, de 11 de mayo (BOCGCongreso de los Diputados, Serie D, número 14, de 12 de mayo de 2004.)

En lo que se refiere a los Reglamentos de los Parlamentos de las Comunidades Autónomas, han de citarse las siguientes modificaciones: la reforma de la Disposición Adicional Tercera del Reglamento del Parlamento de Andalucía para compensar la infrarrepresentación de los Grupos Parlamentarios en la Mesa de la Cámara (BOJA n. ${ }^{\circ}$ 105, de 31 de mayo; BOE n. ${ }^{\circ} 140$, de 10 de junio) y la reforma del artículo 44.2 del Reglamento de la Asamblea de Extremadura para crear la Comisión Permanente de control de la Corporación Extremeña de Medios Audiovisuales (DOE n. ${ }^{\circ}$ 144, de 11 de diciembre de 2004, BOE n. ${ }^{\circ} 315$, de 31 de diciembre).

Por lo que respecta a la actividad legislativa de las Cortes Generales, se aprobaron a lo largo de 2004 las siguientes Leyes:

La Ley Orgánica 1/2004, de 28 de diciembre, de medidas de protección integral contra la violencia de género (BOE n. ${ }^{\circ} 313$, de 29 de diciembre); la Ley Orgánica 2/2004, de 28 de diciembre, por la que se modifica la Ley Orgánica 6/1985, de 1 de julio, del Poder Judicial (BOE n. ${ }^{\circ}$ 313, de 29 de diciembre); la Ley Orgánica 3/2004; de 28 de diciembre, por la que se modifica la Ley Orgánica 3/1980, de 22 de abril del Consejo de Estado (BOE n. ${ }^{\circ} 313$, de 29 de diciembre).

Además, se aprobaron la Ley 1/2004, de 21 de diciembre, de horarios comerciales (BOE n. ${ }^{\circ} 307$, de 22 de diciembre) y la Ley 3/2004, de 29 de diciembre, por la que se establecen medidas de luchas contra la 
morosidad en las operaciones comerciales (BOE n. ${ }^{\circ} 314$, de 30 de diciembre).

En lo que a los Presupuestos del Estado se refiere, se aprobó la Ley 2/2004 de Presupuestos Generales del Estado para el año 2005 (BOE n. ${ }^{\circ}$ 312, de 28 de diciembre de 2004; corrección de errores en BOE n. ${ }^{\circ} 50$, de 28 de febrero de 2005). El Gobierno renunció a presentar la ya tradicional Ley de medidas fiscales, administrativas y del orden social. Sí se aprobó la Ley 4/2004, de 29 de diciembre, de modificación de tasas y de beneficios fiscales de acontecimientos de excepcional interés público (BOE n. ${ }^{\circ} 314$, de 30 de diciembre).

En el ámbito autonómico, deben mencionarse las siguientes Leyes presupuestarias:

Ley $2 / 2004$, de 28 de diciembre, de presupuestos de la Comunidad Autónoma de Andalucía para el año 2005 (BOJA n. ${ }^{\circ} 255$, de 31 de diciembre de 2004); Ley 11/2004, de 23 de diciembre, de presupuestos de la Comunidad Autónoma de Aragón para el año 2005 (BOA n. ${ }^{\circ}$ 153, de 31 de diciembre de 2004); Ley 5/2004, de 29 de diciembre, de presupuestos generales de la Comunidad Autónoma de Canarias para el año 2005 (BOCA n. ${ }^{\circ}$ 254, de 31 de diciembre de 2004); Ley 6/2004, de 27 de diciembre, de Presupuestos Generales de la Comunidad Autónoma de Cantabria para el año 2005 (BOC n. ${ }^{\circ}$ 252, de 31 de diciembre de 2004); Ley 10/2004, de 28 de diciembre, de Presupuestos Generales de la Comunidad de Castilla y León para el año 2005 (BOCL n. ${ }^{\circ} 252$, de 31 de diciembre de 2004); Ley 12/2004, de 23 de diciembre, de presupuestos generales de la Junta de Comunidades de Castilla-La Mancha para el año 2005 (DOCM n. ${ }^{\circ}$ 247, de 30 de diciembre de 2004); Ley 11/2004, de 27 de diciembre, de presupuestos de la Generalidad de Cataluña para 2005 (DOG n. ${ }^{\circ}$ 4292, de 31 de diciembre de 2004); Ley 9/2004, de 27 de diciembre, de presupuestos generales de la Comunidad Autónoma de Extremadura para 2005 (DOE extraordinario n. ${ }^{\circ} 4$, de 31 de diciembre de 2004); Ley 13/2004, de 29 de diciembre, de presupuestos generales de la Comunidad Autónoma de Galicia para el año 2005 (DOG n. ${ }^{\circ} 253$, de 30 de diciembre de 2004); Ley 7/2004, de 23 de diciembre, de presupuestos generales de la Comunidad Autónoma de las Illes Balears para el año 2005 (BOBA n. ${ }^{\circ}$ 186, de 30 de diciembre de 2004); Ley 8/2004, de 22 de diciembre, de presupuestos generales de la Comunidad Autónoma de La Rioja para el año 2005 (BOR n. ${ }^{\circ} 167$ de 30 de diciembre de 2004); Ley 1/2004, de 31 de mayo, de presupuestos generales de la Comunidad de Madrid para 2005 (BOCM n. ${ }^{\circ}$ 297, de 14 de diciembre); Ley Foral 18/2004, de 29 de diciembre, de presupuestos generales de Navarra para el año 2005 (BON n. ${ }^{\circ}$ 157, de 31 de diciembre de 2004); Ley 10/2004, de 28 de diciembre, por la que se aprueban los presupuestos generales de la Comunidad Autónoma del País Vasco para el ejercicio 2005 (BOPV n. ${ }^{\circ} 250$, de 31 de diciembre); Ley 5/2004, de 28 de diciembre, de presupuestos ge- 
nerales del Principado de Asturias para 2005 (BOPA n. ${ }^{\circ} 302$, de 31 de diciembre de 2004); Ley 14/2004, de 29 de diciembre, de presupuestos de la Generalitat Valenciana para el ejercicio 2005 (DOGV n. ${ }^{\circ}$ 4915, de 31 de diciembre).

A propósito de los Órganos Auxilares de las Cortes Generales, el Defensor del Pueblo presentó ante la Comisión Mixta para las Relaciones con el Defensor del Pueblo el Informe correspondiente al año $2003^{1}$ en el que se reseña, entre otras cosas, lo siguiente:

«El número de quejas recibidas durante 2003, sin computar las más de 36.000 derivadas del caso Iraq, fue de 17.389, de las que 12.612 tenían origen individual, 4.612 carácter de colectivas y 165 lo fueron de oficio. Un total que se sitúa entre los registrados en el ejercicio 2001 (13.365) y el 2002 (21.191).

Los datos ofrecidos también señalan otras características de las quejas: se aprecia una cifra superior de las presentadas por hombres en relación con las presentadas por mujeres, al igual que sucediera en los informes precedentes; de igual modo, se vuelve a comprobar que la inmensa mayoría procede de territorio español, y el porcentaje por comunidades repite la Comunidad de Madrid como la de mayor peso en cuanto a procedencia de quejas $(33,2 \%)$; y por sectores de actividad, es preciso destacar las quejas totales relativas a inmigración/emigración (3.818), Administración de justicia (1.726), función pública (1.593) y cuestiones sanitarias (1.495).

Además de lo anotado sobre la gran cantidad de peticiones relacionadas con motivo del conflicto de Iraq, de las 17.389 quejas efectivamente registradas, se admitieron a trámite 6.249 , no se admitieron 9.476 y se encontraban pendientes de tomar una decisión, en este sentido, por causas diversas, otras 1.664. Los motivos de inadmisión más frecuentes fueron los de falta de indicios de irregularidad administrativa, no haberse observado actuación inadecuada de los poderes públicos y haberse producido sentencia firme o intervención judicial.

La situación de tramitación para las quejas admitidas, a 31 de diciembre del ejercicio cuyo informe se presenta, es la de: concluidas $(41,3 \%)$, en suspenso $(0,3 \%)$, y en trámite $(58,4 \%)$. Las que se encontraban pendientes de tomar una decisión lo estaban porque, bien requerían información adicional solicitada al interesado, bien requerían algún trámite o estudio complementario, o bien había de subsanarse algún defecto de forma.

En cuanto a la situación de las quejas procedentes de anteriores ejercicios, 2.194 acabaron siendo admitidas en 2003, se reabrieron otras 348 y se repusieron 24 cuya tramitación se encontraba suspendida. Además del estudio y, en su caso, tramitación de las quejas, los servicios de la Institución programaron, realizaron y supervisaron durante el ejer-

\footnotetext{
${ }^{1}$ Véase en http://www.defensordelpueblo.es/index.asp?destino=informes1.asp
} 
cicio 2003 dos estudios de carácter monográfico. Uno, sobre La escolarización del alumnado de origen inmigrante en España: análisis descriptivo y estudio empírico, y otro, sobre Funcionarios interinos y personal eventual: la provisionalidad y temporalidad en el empleo público.

La actividad ordinaria desarrollada por la Institución en el ejercicio 2003 culminó en una serie de resoluciones dirigidas a las diferentes administraciones concernidas. Así, se formularon en total 154 recomendaciones, 228 sugerencias, 103 recordatorios de deberes legales y 1 advertencia. Aunque todavía quedaba un número apreciable de resoluciones sobre las que no se habían pronunciado las administraciones, a 31 de diciembre de 2003 habían sido admitidas casi la mitad de las recomendaciones y sugerencias formuladas, y se habían rechazado en torno a un 23 por ciento. El citado estudio sobre funcionarios interinos y personal eventual dio lugar, además, a un total de 168 recomendaciones dirigidas a las administraciones públicas.

En lo que respecta a otro de los órganos auxiliares, el Tribunal de Cuentas, por Real Decreto 2215/2004, de 25 de noviembre (BOE n. ${ }^{\circ} 285$, de 26 de noviembre) se nombró Presidente a Ubaldo Nieto de Alba.

En el ámbito autonómico cabe citar la Ley 4/2004, de 2 de abril, de Sindicatura de Cuentas de las Illes Balears (BOIB n. ${ }^{\circ}$ 50, de 10 de abril).

El Gobierno de la Nación tomó posesión el 18 de abril, tras la investidura de José Luis Rodríguez Zapatero como Presidente celebrada los días 15 y 16 de abril y en la que obtuvo 183 votos a favor (de los 164 diputados del PSOE, los ocho de ERC, los cinco de IU-ICV, los tres de $\mathrm{CC}$, los dos del BNG y el de CHA), 148 en contra (de los diputados del PP) y 19 abstenciones (10 de CiU, 7 del PNV y los de EA y NB).

Los titulares de las carteras ministeriales son: María Teresa Fernández de la Vega Vicepresidenta Primera y Ministra de la Presidencia; Pedro Solbes Vicepresidente Segundo y Ministro de Economía y Hacienda; Miguel Ángel Moratinos Ministro de Asuntos Exteriores; Juan Fernando López Aguilar Ministro de Justicia; José Bono Ministro de Defensa; José Antonio Alonso Ministro del Interior; Magdalena Álvarez Ministra de Fomento; María Antonia Trujillo Ministra de Vivienda; María Jesús San Segundo Ministra de Educación y Ciencia; Carmen Calvo Ministra de Cultura; Jesús Caldera Ministro de Trabajo y Asuntos Sociales; José Montilla Ministro de Industria, Comercio y Turismo; Elena Espinosa Ministra de Agricultura, Pesca y Alimentación; Jordi Sevilla Ministro de Administraciones Públicas; Elena Salgado Ministra de Sanidad y Cristina Narbona Ministra de Medio Ambiente.

Por Real Decreto 1194/2004, de 14 de mayo (BOE n. ${ }^{\circ} 120$, de 18 de mayo) se determina la composición de las Comisiones Delegadas del Gobierno. Además de las que se constituyan por ley, serán las si- 
guientes: a) Comisión Delegada del Gobierno para Situaciones de Crisis b) Comisión Delegada del Gobierno para Asuntos Económicos c) Comisión Delegada del Gobierno para Asuntos de Investigación Científica y Desarrollo e Innovación Tecnológica d) Comisión Delegada del Gobierno para Política Autonómica.

Quedan suprimidas: a) La Comisión Delegada del Gobierno para Política Exterior b) La Comisión Delegada del Gobierno para la Seguridad del Estado c) La Comisión Delegada del Gobierno para Asuntos Culturales d) La Comisión de Política Económica prevista en el artículo 3 del Real Decreto 685/2000, de 12 de mayo.

Por lo que a la actividad legislativa del Gobierno se refiere, se aprobaron once Decretos-Ley y ocho Decretos Legislativos

Real Decreto-Ley $1 / 2004$, de 7 de mayo, por el que se aplaza la entrada en vigor de la Ley 39/2003, de 17 de noviembre, del Sector Ferroviario (BOE n. ${ }^{\circ} 114$, de 11 de mayo), convalidado el 20 de mayo (BOE n. ${ }^{\circ}$ 127, de 26 de mayo); Real Decreto-Ley 2/2004, de 18 de junio, por el que se modifica la Ley 10/2001, de 5 de julio, del Plan Hidrológico Nacional (BOE n. ${ }^{\circ} 148$, de 19 de junio), convalidado el 29 de junio (BOE n. ${ }^{\circ}$ 160, de 3 de julio); Real Decreto-Ley 3/2004, de 25 de junio, para la racionalización de la regulación del salario mínimo interprofesional y para el incremento de su cuantía (BOE $n .^{\circ} 154$, de 26 de junio), convalidado el 21 de julio (BOE n. ${ }^{\circ} 178$, de 24 de julio); Real Decreto-Ley 4/2004, de 2 de julio, por el que se adoptan determinadas medidas relacionadas con los daños ocasionados por el accidente del buque Prestige (BOE n. ${ }^{\circ}$ 160, de 3 de julio), convalidado el 21 de julio (BOE n. ${ }^{\circ} 178$, de 24 de julio); Real Decreto-Ley 5/2004, de 27 de agosto, por el que se regula el régimen del comercio de derechos de emisión de gases de efecto invernadero (BOE n. ${ }^{\circ} 208$, de 28 de agosto), convalidado el 16 de septiembre (BOE n. ${ }^{\circ} 228$, de 21 de septiembre); Real Decreto-Ley 6/2004, de 17 septiembre, por el que se adoptan medidas urgentes para reparar los daños causados por los incendios e inundaciones acaecidos en las Comunidades Autónomas de Aragón, Cataluña, Andalucía, Comunidad Foral de Navarra y Comunidad Valenciana (BOE n. ${ }^{\circ} 226$, de 18 de septiembre), convalidado el 30 de septiembre (BOE n. ${ }^{\circ} 242$, de 7 de octubre); Real Decreto-Ley $7 / 2004$, de 27 de septiembre, por el que se concede un crédito extraordinario por importe de 2.500.034.925 euros para atender al pago de la liquidación del sistema de financiación para el período 1997-2001 correspondiente a la Comunidad Autónoma de Andalucía y se adoptan disposiciones sobre la deuda de RENFE y el aval del Estado al préstamo otorgado a la República de Argentina (BOE n. ${ }^{\circ} 234$, de 28 de septiembre), convalidado el 26 de octubre (BOE n. ${ }^{\circ} 266$, de 4 de noviembre); Real Decreto Ley $8 / 2004$, de 5 de noviembre, sobre indemnizaciones a los participantes en operaciones internacionales de paz y seguridad (BOE $n .^{\circ}$ 271 , de 10 de noviembre, corrección de errores en el BOE n. ${ }^{\circ} 280$, de 20 
de noviembre), convalidado el 2 de diciembre (BOE n. ${ }^{\circ} 298$, de 11 de diciembre); Real Decreto Ley 9/2004, de 3 de diciembre, por el que se determina el plazo para la ejecución de los procesos previstos en la Ley 16/2001, de 21 de noviembre, por la que se establece un proceso extraordinario de consolidación y provisión de plazas de personal estatutario en las Instituciones Sanitarias de la Seguridad Social de los Servicios de Salud del Sistema Nacional de Salud (BOE n. ${ }^{\circ} 292$, de 4 de diciembre), convalidado el 22 de diciembre (BOE n. ${ }^{\circ} 314$, de 30 de diciembre); Real Decreto Ley 10/2004, de 23 de diciembre, por el que se amplía el plazo de adaptación de las comisiones de control de los planes de pensiones de empleo (BOE n. ${ }^{\circ} 312$, de 28 de diciembre), convalidado el 28 de diciembre (BOE n. ${ }^{\circ} 11$, de 13 de enero de 2005); Real Decreto Ley 11/2004, de 23 de diciembre, por el que se modifica, en materia de pensiones públicas, la Ley de Presupuestos Generales del Estado para el año 2005 (BOE n. ${ }^{\circ}$ 312 , de 28 de diciembre de 2004), convalidado el 28 de diciembre (BOE n. ${ }^{\circ} 11$, de 13 de enero de 2005).

Real Decreto legislativo 1/2004, de 5 de marzo, por el que se aprueba el texto refundido de la Ley del Catastro Inmobiliario (BOE n. ${ }^{\circ}$, de 8 de marzo); Real Decreto legislativo 2/2004, de 5 de marzo, por el que se aprueba el texto refundido de la Ley Reguladora de las Haciendas Locales (BOE n. ${ }^{\circ} 59$, de 9 de marzo, corrección de errores en el BOE n. ${ }^{\circ} 63$, de 13 de marzo); Real Decreto legislativo 3/2004, de 5 de marzo, por el que se aprueba el texto refundido de la ley del Impuesto sobre la Renta de las Personas Físicas (BOE n. ${ }^{\circ}$ 60, de 10 de marzo, corrección de errores en el BOE n. ${ }^{\circ}$ 61, de 11 de marzo); Real Decreto legislativo 4/2004, de 5 de marzo, por el que se aprueba el texto refundido de la Ley del Impuesto sobre Sociedades (BOE n. ${ }^{\circ}$ 61, de 15 de marzo); Real Decreto legislativo 5/2004, de 5 de marzo, por el que se aprueba el texto refundido de la Ley del Impuesto sobre la Renta de no residentes (BOE n. ${ }^{\circ} 62$, de 12 de marzo); Real Decreto Legislativo 6/2004, de 29 de octubre, por el que se aprueba el texto refundido de la Ley de ordenación y supervisión de los seguros privados (BOE n. ${ }^{\circ} 267$, de 5 de noviembre); Real Decreto Legislativo 7/2004, de 29 de octubre, por el que se aprueba el texto refundido del Estatuto Legal del Consorcio de Compensación de Seguros (BOE n. ${ }^{\circ} 267$, de 5 de noviembre); Real Decreto Legislativo 8/2004, de 29 de octubre, por el que se aprueba el texto refundido de la Ley sobre responsabilidad civil y seguro en la circulación de vehículos a motor (BOE n. ${ }^{\circ} 267$, de 5 de noviembre).

En el ámbito autonómico es necesario recordar que, tras las elecciones parlamentarias andaluzas antes mencionadas, Manuel Chaves fue elegido Presidente de la Comunidad Autónoma con el voto favorable de 61 (PSOE) de los 109 diputados que integran la Cámara; se registraron 36 votos en contra (PP) y la abstención de 11 parlamentarios (6 de IU y 5 PA).

En Cataluña se produjo una remodelación del Gobierno el día 28 de enero, cesando Carod Rovira como conseller en cap al tiempo que se 
distribuyen las funciones y competencias de ese cargo entre las consejerías de Gobernación, Enseñanza, Bienestar Social y Familia, y Presidencia.

Ha de recordarse la aprobación de la Ley Foral 14/2004, de 3 de diciembre, del Gobierno de Navarra y de su Presidente; la Ley Foral 15/2004, de 3 de diciembre, de la Administración de la Comunidad Foral de Navarra y la Ley Foral 16/2004, de 3 de diciembre, de medidas relativas al personal al servicio de las Administraciones Públicas de Navarra (las tres en el BON n. ${ }^{\circ} 115$, de 15 de diciembre de 2004; BOE n. ${ }^{\circ} 27$, de 1 de febrero de 2005),

Respecto de los órganos consultivos del Gobierno ha de citarse la Ley Orgánica 3/2004; de 28 de diciembre, por la que se modifica la Ley Orgánica 3/1980, de 22 de abril del Consejo de Estado (BOE n. ${ }^{\circ} 313$, de 29 de diciembre, corrección de errores en el BOE n. ${ }^{\circ} 46$, de 23 de febrero de 2005). Previamente, por Real Decreto 572/2004, de 19 de abril, se nombró Presidente del Consejo de Estado a Francisco Rubio Llorente (BOE n. ${ }^{\circ}$ 96, de 20 de abril).

En el ámbito autonómico se aprobó la Ley 1/2004, de 21 de octubre, del Consejo Consultivo del Principado de Asturias (BOPA n. ${ }^{\circ} 256$, de 4 de noviembre).

En lo que se respecta al Poder Judicial y a la Administración de Justicia, ha de mencionarse la Ley Orgánica 2/2004, de 28 de diciembre, por la que se modifica la Ley Orgánica 6/1985, de 1 de julio del Poder Judicial (BOE n. ${ }^{\circ} 313$, de 29 de diciembre);

El artículo 127 queda redactado del modo siguiente: "Será de la competencia del Pleno del Consejo General del Poder Judicial: 1. La propuesta de nombramiento por mayoría de tres quintos de sus miembros de: a) El Presidente del Tribunal Supremo y del Consejo General del Poder Judicial y el Vicepresidente de este último. b) Los miembros del Tribunal Constitucional cuya designación le corresponde. c) Los Presidentes de Sala y Magistrados del Tribunal Supremo, así como los Presidentes de los Tribunales Superiores de Justicia de las Comunidades Autónomas. d) El Magistrado de la Sala Segunda de lo Penal o Tercera de lo Contencioso-Administrativo, del Tribunal Supremo, competente para conocer de la autorización de las actividades del Centro Nacional de Inteligencia que afecten a los derechos fundamentales reconocidos en el artículo 18.2 y 3 de la Constitución, así como la del Magistrado de dichas Salas del Tribunal Supremo que lo sustituya en caso de vacancia, ausencia o imposibilidad. Para el cómputo de la mayoría cualificada exigida en este apartado se tomará siempre como base la totalidad de los veintiún miembros integrantes del Consejo General del Poder Judicial, conforme a lo previsto en el artículo 111 de esta Ley. Para efectuar dichas 
propuestas de nombramiento previstas en este apartado, el Pleno del Consejo General del Poder Judicial velará, en todo caso, por el cumplimiento de los principios de mérito y capacidad. 2. La propuesta de nombramiento de los demás cargos de designación discrecional. 3. Evacuar la audiencia prevista en el artículo 124.4 de la Constitución sobre nombramiento del Fiscal General del Estado. 4. Resolver los recursos de alzada interpuestos contra los acuerdos de la Comisión Permanente, de la Comisión Disciplinaria y de las Salas de Gobierno de los Tribunales Superiores de Justicia y de los órganos de gobierno de los Tribunales y Juzgados. 5. Resolver los expedientes de rehabilitación instruidos por la Comisión Disciplinaria. 6. Evacuar los informes previstos en la Ley y ejercer la potestad reglamentaria atribuida por la Ley al Consejo General del Poder Judicial. 7. Acordar, en los casos legalmente establecidos, la separación y jubilación de los Jueces y Magistrados en los supuestos no previstos en el artículo 131.3. 8. Elegir y nombrar los Vocales componentes de las Comisiones y Delegaciones. 9. Aprobar la memoria anual que con motivo de la apertura del año judicial leerá su Presidente sobre el estado de la Administración de Justicia. 10. Elaborar el Presupuesto del Consejo General del Poder Judicial, que se integrará en los Generales del Estado, en una sección independiente. 11. Dirigir la ejecución del presupuesto del Consejo y controlar su cumplimiento. 12. Cualesquiera otras funciones que correspondan al Consejo General del Poder Judicial y no se hallen expresamente atribuidas a otros órganos del mismo".

Dos. Se añade un número 5 al artículo 200, con el siguiente contenido:

«5. Los Magistrados del Tribunal Supremo, una vez jubilados, serán designados Magistrados eméritos en el Tribunal Supremo cuando así lo soliciten, siempre que reúnan los requisitos legalmente establecidos y de acuerdo con las necesidades de refuerzo en la Sala correspondiente.".

Tres. El apartado 3 del artículo 335 tendrá la siguiente redacción:

«3. La plaza de Jefe del Servicio de Inspección del Consejo General del Poder Judicial se proveerá por un Magistrado del Tribunal Supremo con una antigüedad en la categoría de dos años o por un Magistrado con diez años de servicios en la categoría. En este último caso, mientras desempeñe el cargo, tendrá la consideración de Magistrado del Tribunal Supremo".

Cuatro. Se añaden sendos apartados 4 y 5 al artículo 348 bis, con la siguiente redacción: «4. Fiscal General del Estado. 5. Jefe del Servicio de Inspección del Consejo General del Poder Judicial».

Cinco. Se añade una nueva letra e) al artículo 352, con la siguiente redacción: «e) Jefe del Servicio de Inspección del Consejo General del Poder Judicial».

Por lo que al Tribunal Constitucional se refiere, ha de aludirse, en primer lugar, al nombramiento de cuatro nuevos Magistrados: por Real Decreto 1404/2004, de 8 de junio, se nombra Magistrado del Tribunal Constitucional a Manuel Aragón Reyes; por Real Decreto 1405/2004, de 8 de junio, se nombró Magistrado del Tribunal Constitucional a Pablo 
Pérez Tremps; por Real Decreto 1406/2004, de 8 de junio, se nombra Magistrado del Tribunal Constitucional a Ramón Rodríguez Arribas, y por Real Decreto 1407/2004, de 8 de junio, se nombra Magistrado del Tribunal Constitucional a Pascual Sala Sánchez; los dos primeros a propuesta del Gobierno y los dos últimos a propuesta del Consejo General del Poder Judicial (los nombramientos aparecen en el BOE n. ${ }^{\circ}$ 139, de 9 de junio). Estos Magistrados cubrieron las bajas de Manuel Jiménez de Parga, Tomás Vives Antón, Pablo García Manzano y Pablo Cachón Villar (los ceses aparecen en el BOE n. ${ }^{\circ} 139$, de 9 de junio).

Por Real Decreto 1470/2004, de 15 de junio, se nombró Presidenta del Tribunal Constitucional a María Emilia Casas Baamonde y por Real Decreto $1471 / 2004$, de 15 de junio, se nombra Vicepresidente del Tribunal Constitucional a Guillermo Jiménez Sánchez (BOE n. ${ }^{\circ}$ 145, de 16 de junio).

Por Acuerdo de 16 de junio del Pleno del Tribunal (BOE n. ${ }^{\circ}$ 151, de 23 de junio), se dispone la composición de las Salas y Secciones del Tribunal:

La Sala Primera estará integrada por María Emilia Casas Baamonde, Javier Delgado Barrio, Roberto García-Calvo, Jorge Rodríguez-Zapata, Manuel Aragón Reyes y Pablo Pérez Tremps; la Sección Primera por Emilia Casas Baamonde, Javier Delgado Barrio y Manuel Aragón Reyes y su Sección Segunda por Jorge Rodríguez-Zapata, Roberto García-Calvo y Pablo Pérez Tremps. La Sala Segunda estará integrada por Guillermo Jiménez Sánchez, Vicente Conde Martín de Hijas, Elisa Pérez Vera, Eugeni Gay Montalvo, Ramón Rodríguez Arribas y Pascual Sala Sánchez; la Sección Tercera por Guillermo Jiménez Sánchez, Eugeni Gay Montalvo y Ramón Rodríguez Arribas y la Sección Cuarta por Vicente Conde Martín de Hijas, Elisa Pérez Vera y Pascual Sala Sánchez.

Previamente a estos nombramientos, el Pleno del Tribunal Constitucional, en su reunión de 3 de febrero, acordó

«Primero. Declarar que las resoluciones dictadas por el Tribunal Constitucional en los recursos de amparo no pueden ser enjuiciadas por ningún órgano del Poder Judicial dado que sólo a este Tribunal corresponde, conforme a la Constitución y a su Ley Orgánica, resolver tales recursos.

Segundo. Asimismo declarar que el enjuiciamiento de las resoluciones recaídas en recursos de amparo, realizado por vía de la acción de responsabilidad civil, constituye una invasión de la jurisdicción, exclusiva y excluyente, atribuida a este Tribunal Constitucional por la Constitución».

En lo que respecta a la tarea jurisdiccional del Tribunal en materia de control de constitucionalidad han de mencionarse las siguientes sentencias: 
En la STC 24/2004, de 24 de febrero, ante una cuestión de inconstitucionalidad respecto del artículo 563 de la Ley Orgánica 10/1995, del Código penal, el Tribunal declara que el inciso primero de dicho precepto es constitucional interpretado en el siguiente sentido:

«...a tenor del art. 563 CP las armas cuya tenencia se prohíbe penalmente son, exclusivamente, aquellas que cumplan los siguientes requisitos: en primer lugar, y aunque resulte obvio afirmarlo, que sean materialmente armas (pues no todos los objetos prohibidos con ese nombre en la norma administrativa lo son); en segundo lugar, que su tenencia se prohíba por una norma extrapenal con rango de ley o por el reglamento al que la ley se remite, debiendo excluirse del ámbito de prohibición del art. $563 \mathrm{CP}$ todas aquellas armas que se introduzcan en el catálogo de los arts. 4 y 5 del Reglamento de armas mediante una Orden ministerial conforme a lo previsto en la disposición final cuarta, por impedirlo la reserva formal de ley que rige en material penal; en tercer lugar, que posean una especial potencialidad lesiva y, por último, que la tenencia se produzca en condiciones o circunstancias que la conviertan, en el caso concreto, en especialmente peligrosa para la seguridad ciudadana, quedando excluida la intervención del Derecho penal cuando no concurra realmente ese concreto peligro sin perjuicio de que se acuda, en ese caso, al Derecho administrativo sancionador (STC 111/1999, de 14 de junio, FJ 3)» (F 8).

En la STC 37/2004, de 11 de marzo, el Tribunal estimó la cuestión de inconstitucionalidad $y$, en su virtud, declaró inconstitucional y nulo el artículo 135 b), último inciso, del Real Decreto Legislativo 781/1986, de 18 de abril, por el que se aprueba el Texto refundido de las disposiciones legales vigentes en materia de régimen local, en la medida en que imponía un límite de edad máximo para los aspirantes a ocupar puestos de la función pública local (no exceder de aquella edad en que falten menos de diez años para la jubilación forzosa determinada por la legislación básica en materia de función pública).

En la STC 48/2004, de 25 de marzo, se estimaron las cuestiones de inconstitucionalidad planteadas por la Sala de lo Contencioso-Administrativo del Tribunal Superior de Justicia de Cataluña (Sección Quinta) y, en consecuencia, se declaró inconstitucional y nulo el artículo 12, en sus dos apartados, de la Ley del Parlamento de Cataluña 5/1987, de 4 de abril, de régimen provisional de las competencias de las Diputaciones provinciales.

La STC 51/2004, de 13 de abril, se pronunció sobre las cuestiones de inconstitucionalidad planteadas por la Sala de lo Contencioso-Administrativo del Tribunal Superior de Justicia de Cataluña en relación con la disposición transitoria octava del texto refundido de la legislación vi- 
gente en Cataluña en materia urbanística, aprobado por Decreto Legislativo 1/1990, de 12 de julio, declarando que es inconstitucional y, en consecuencia, nulo el adverbio "també» incluido en el inciso segundo de la disposición transitoria octava, en la medida en que añade a la competencia municipal de iniciativa la de la Comisión de Urbanismo de Barcelona cuando la modificación del Plan afecte a elementos con una incidencia territorial limitada a un término municipal.

La STC $110 / 2004$, de 30 de junio, puso fin a la cuestión de inconstitucionalidad 4891/99, promovida por la Sala de lo Social del Tribunal Superior de Justicia de las Illes Balears, respecto del artículo 6.5 de la Ley de la Comunidad Autónoma de las Illes Balears 5/1996, de 18 de diciembre, de medidas tributarias y administrativas, declarando inconstitucional y nulo ese precepto. Estima el Tribunal que las limitaciones presupuestarias no pueden servir para consagrar un régimen retributivo distinto para determinados empleados públicos dependientes de la misma Administración y que ocupan puestos similares.

En la STC 179/2004, de 18 de octubre, el Tribunal respondió a la cuestión interna de inconstitucionalidad planteada por el Pleno en relación con los artículos 108, párrafo 2, de la Ley Orgánica 4/1987, de 15 de julio, de la competencia y organización de la jurisdicción militar, y 127, párrafo 1, de la Ley Orgánica 2/1989, de 13 de abril, procesal militar, declararando la inconstitucionalidad y consiguiente nulidad del artículo 108, párrafo 2, así como del artículo 127, párrafo 1, de la Ley Orgánica 2/1989, de 13 de abril, procesal militar, en el inciso "excepto cuando ofendido e inculpado sean militares y exista entre ellos relación jerárquica de subordinación". Y es que, a juicio del Tribunal, la prohibición del ejercicio de la acción penal, en calidad de acusador particular, así como de la acción civil derivada de delito o falta, en el ámbito del proceso militar, cuando ofendido e inculpado sean militares y exista entre ellos relación jerárquica de subordinación, contenida en dichos preceptos, no encuentra justificación constitucional suficiente en la protección de la disciplina militar y en el principio jerárquico en que se asienta la organización de las Fuerzas Armadas y de los institutos armados de naturaleza militar, ni resulta proporcionada a la pretendida finalidad de preservar la disciplina militar, por lo que conculca el principio constitucional de igualdad en la ley reconocido por el artículo $14 \mathrm{CE}$ y el derecho fundamental a la tutela judicial efectiva sin indefensión garantizado por el artículo 24.1 CE, en su vertiente de acceso a la jurisdicción.

La STC 193/2004, de 4 de noviembre, puso fin a la cuestión de inconstitucionalidad planteada por la Sección Segunda de la Sala de lo 
Contencioso-Administrativo del Tribunal Superior de Justicia de CastiIla-La Mancha sobre el artículo 90.2 de la Ley 39/1988, de 28 de diciembre, reguladora de las haciendas locales, en su redacción anterior a la modificación operada por la Ley 22/1993, de 29 de diciembre, por su posible vulneración del artículo 14, en relación con el artículo 31.1, ambos de la Constitución española. El Tribunal declaró inconstitucional y nulo el artículo 90.2 de la Ley $39 / 1988$, sólo en la medida en que excluye del prorrateo por trimestres de las cuotas del impuesto de actividades económicas los supuestos de baja por cese en el ejercicio de actividades económicas.

La STC 253/2004, de 23 de diciembre, estimó la cuestión de inconstitucionalidad planteada por el Juzgado de lo Social núm. 1 de Pontevedra respecto del párrafo segundo del artículo 12.4 de la Ley del Estatuto de los Trabajadores, en la versión del texto refundido de 24 de marzo de 1995, declarando inconstitucional y nulo dicho párrafo en cuanto establece que para determinar los periodos de cotización de las prestaciones de Seguridad Social, incluida la de protección por desempleo, se computarán exclusivamente las horas trabajadas.

Al respecto, entiende el Tribunal que el principio de contributividad que informa nuestro sistema de Seguridad Social justifica que el legislador establezca (como lo hace en la norma cuestionada) que las bases reguladoras de las prestaciones de Seguridad Social se calculen en función de lo efectivamente cotizado, de donde resultará, lógicamente, una prestación de cuantía inferior para los trabajadores contratados a tiempo parcial, por comparación con los trabajadores que desempeñen ese mismo trabajo a jornada completa. Pero lo que no aparece justificado es que se establezca una diferencia de trato entre trabajadores a tiempo completo y trabajadores a tiempo parcial en cuanto al cumplimiento del requisito de carencia para el acceso a las prestaciones contributivas de Seguridad Social, diferenciación, por tanto, arbitraria y que además conduce a un resultado desproporcionado, al dificultar el acceso a la protección de la Seguridad Social de los trabajadores contratados a tiempo parcial, situación ésta que afecta predominantemente a las mujeres trabajadoras, como revelan los datos estadísticos.

La STC 255/2004, de 22 de diciembre, estimó las cuestiones de inconstitucionalidad planteadas por la Sala de lo Contencioso-Administrativo del Tribunal Superior de Justicia del País Vasco y, en consecuencia, declaró inconstitucional y nulo tanto el artículo 19.2 b) de la Ley 44/1978, de 8 de septiembre, reguladora del impuesto sobre la renta de las personas físicas (en la redacción dada por la Ley 48/1985, de 27 de diciembre), como el artículo 29 A) de la misma Ley 44/1978 (en la redacción dada por el Real Decreto-ley 6/1988, de 29 de diciembre), 
en el inciso que establece «realizadas con separación de los restantes miembros de la unidad familiar».

El efecto práctico de la norma cuestionada no era otro, para aquellas unidades familiares en las que uno de los miembros satisface a otro rendimientos del trabajo o de actividades profesionales, empresariales o artísticas, que la imposibilidad real de optar por la declaración conjunta o separada, imponiéndose ex lege una declaración única (la del pagador de las rentas que no puede minorar su base en los rendimientos satisfechos a otro miembro de la unidad familiar quien, a su vez, no puede computarlos como propios) que, en realidad, pasa a ser una auténtica declaración conjunta (en tanto que está incorporando a su declaración no sólo sus rendimientos sino también los obtenidos por otro miembro de la unidad familiar), que contradice la doctrina sentada en la STC 45/1989, de 20 de febrero.

\section{ORGANIZACIÓN TERRITORIAL DEL ESTADO}

En el ámbito político-constitucional ha de hacerse mención a los avatares que ha seguido el denominado "Plan Ibarretxe": es preciso recordar, en primer término, que el 25 de octubre de 2003 el Gobierno Vasco aprobó la propuesta de nuevo Estatuto de Autonomía, "basado en la libre asociación con el Estado español», y acordó remitirlo al Parlamento autonómico; el 4 de noviembre de ese año la Mesa del Parlamentó decidió tramitar la propuesta por el procedimiento legislativo común; el día 13 de ese mismo mes el Gobierno de la Nación impugnó ante el Tribunal Constitucional los Acuerdos del Gobierno Vasco y de la Mesa de la Cámara.

Ya en 2004, el Pleno del Tribunal, en el Auto 135/2004, de 20 de abril, resolvió que

"los Acuerdos que se impugnan, como puros actos de tramitación insertados en un procedimiento parlamentario, sólo despliegan efectos ad intra de ese procedimiento en tanto éste no concluya con la aprobación de la norma que a su través pretende generarse. La eventual inconstitucionalidad de los actos parlamentarios sólo es relevante cuando concluyen con una resolución, disposición o acto que se integra en el Ordenamiento (y deberá verificarse con motivo del juicio de constitucionalidad que eventualmente se inste respecto de esa disposición, resolución o acto), o cuando, sin finalizar el procedimiento en el que se insertan, producen una lesión inmediata de derechos fundamentales de los sujetos legitimados para participar en el procedimiento. Aquel control se verificará por vía del recurso y de la cuestión de inconstitucionalidad; éste mediante el recurso de amparo. La impugnación del título $\mathrm{V}$ queda 
descartada, por principio, si pretende dirigirse contra el acto de trámite antes de que el procedimiento concluya, pues, según se ha dicho, el título $\mathrm{V}$, en un entendimiento sistemático de la Ley en la que se incluye, establece un procedimiento de control de constitucionalidad de disposiciones y resoluciones imputables a la Comunidad Autónoma por conducto de los órganos expresivos de su voluntad institucional, supuesto en el que manifiestamente no pueden comprenderse los actos que se insertan en un procedimiento de gestación (incierta) de esa voluntad. Y debe también excluirse una vez finalizado el procedimiento, si éste lo hace con una norma con rango de ley.

En definitiva, en los Acuerdos del Gobierno Vasco de 25 de octubre de 2003 y de la Mesa del Parlamento Vasco de 4 de noviembre de 2003 no concurre el «presupuesto procesal insubsanable de constituir objetos idóneos de la impugnación regulada en el art. 161.2 CE y en el título $\mathrm{V}$ de la Ley Orgánica del Tribunal Constitucional.

En virtud de lo expuesto, el Pleno acuerda la inadmisión de la impugnación y el archivo de las actuaciones».

En el Pleno del Parlamento Vasco de 30 de diciembre de 2004 resultó aprobada la propuesta del nuevo Estatuto político de la Comunidad de Euskadi con los votos favorables del Partido Nacionalista VascoEusko Alkartasuna (33), Izquierda Unida (3) y Sozialista Aberzaleak (3) y los votos contrarios del Partido Popular(18), Partido Socialista (13), Unidad Alavesa (1) y Sozialista Aberzaleak (3).

La propuesta se tramitó ante el Congreso de los Diputados como una iniciativa de reforma de Estatuto de Autonomía y se sometió a debate de totalidad el día 1 de febrero de 2005, siendo rechazada por 313 votos en contra, 29 a favor y 2 abstenciones, quedando, en consecuencia, rechazada la propuesta (Diario de Sesiones del Congreso de los Diputados, n. ${ }^{\circ}$ 65, de 1 de febrero).

Ha de señalarse, en otro orden de cosas, la celebración de la primera Conferencia de Presidentes, que reunió al Presidente del Gobierno con los de las Comunidades y Ciudades Autónomas en la sede del Senado el día 28 de octubre.

Por lo que respecta a las cuestiones legislativas en el ámbito local, ha de recordarse la aprobación del Real Decreto legislativo 2/2004, de 5 de marzo, por el que se aprueba el texto refundido de la Ley Reguladora de las Haciendas Locales (BOE n. ${ }^{\circ} 59$, de 9 de marzo, corrección de errores en el BOE n. ${ }^{\circ} 63$, de 13 de marzo); la Ley 5/2004, de 13 de julio, de modificación de la Ley $2 / 2001$, de 11 de mayo, de creación y gestión de las Áreas Metropolitanas en la Comunidad Valenciana (DOGV n. ${ }^{\circ} 4797$, de 14 de julio; BOE n. ${ }^{\circ}$ 188, de 5 de agosto); la Ley Foral 1/2004, de 29 de octubre, para la actualización del régimen local de Navarra (BON n. ${ }^{\circ} 133$, 
de 5 de noviembre; BOE n. ${ }^{\circ} 289$, de 1 de diciembre) y la ley Foral $17 / 2004$, de 3 de diciembre, por la que se establece la cuantía y fórmula de reparto del Fondo de Participación de las Haciendas Locales en los tributos de Navarra para los ejercicios presupuestarios de 2005 a 2008 (BON n. ${ }^{\circ}$ 150, de 15 de diciembre; BOE n. ${ }^{\circ} 27$, de 1 de febrero).

En el ámbito de la jurisprudencia constitucional han de citarse las siguientes sentencias:

La STC 14/2004, de 13 de febrero, resolvió el recurso de inconstitucionalidad promovido por el Presidente del Gobierno contra dos apartados de la Ley de las Cortes de Aragón 7/1998, de 16 de julio, de ordenación del territorio.

Al respecto, el Tribunal concluye que la normativa básica ha sometido a los residuos generados en el proceso de producción de energía nuclear a un régimen de gestión de efectos supracomunitarios. Esta perspectiva unitaria y abierta a todo el territorio nacional afecta, entre otros aspectos de la gestión de los residuos nucleares a su almacenamiento, de manera que los criterios esenciales de aspectos tales como el emplazamiento de los almacenes, las garantías de seguridad de estas instalaciones, o las del transporte de los residuos hasta las mismas desde los centros de producción, se incluyen en ese ámbito básico. Corresponde, en suma, al legislador básico, en razón a las características estructurales de que se pretenda dotar al sector de la energía nuclear que le corresponde ordenar, decidir si los residuos generados en una Comunidad Autónoma han de ser necesariamente almacenados en la misma Comunidad, o si, por el contrario, resulta más adecuado distribuir estratégicamente los centros de producción y los almacenes de residuos de esta modalidad de energía, teniendo como referencia el conjunto del territorio nacional, según las pautas que se estimen convenientes. Habida cuenta de que el precepto de la Ley aragonesa configura un modelo de almacenamiento de residuos excluyente de aquéllos que pudieran producirse en otras Comunidades Autónomas, incurre en infracción del orden constitucional de competencias, por lo que procede declarar inconstitucional y nulo el número 222 de la directriz duodécima, apartado II, de la letra D) de los principios del anexo de la Ley de las Cortes de Aragón 7/1998, de 16 de julio, de ordenación del territorio. Directrices generales.

La STC 38/2004, de 11 de marzo, puso fin al recurso de inconstitucionalidad promovido por el Gobierno de la Nación contra la Ley de Asturias 4/1996, de 13 de diciembre, que reformó una disposición de la Ley $3 / 1985$, de 26 de diciembre, de ordenación de la función pública del Principado.

En palabras del Tribunal, el sistema de acceso a la función pública diseñado en el punto dos de la disposición adicional impugnada ha de ca- 
lificarse de restringido, cerrado o específico, pues al establecer cuáles habrán de constituir los ejercicios integrantes de las pruebas de acceso se refiere exclusivamente a quienes, en la fecha de entrada en vigor de la Ley de Asturias 3/1985, de 26 de diciembre, de ordenación de la función pública de la Administración del Principado, tuvieran la condición de personal laboral fijo. En suma, quedan excluidos los "aspirantes libres" que no prestan servicios como personal laboral fijo, entre quienes se encuentran incluso los funcionarios interinos. El Tribunal concluye que es inconstitucionalidad y nulo el punto dos de la disposición adicional octava de la Ley de Asturias 3/1985, de 26 de diciembre.

La STC 47/2004, de 25 de marzo, estimó el recurso de inconstitucionalidad promovido por el Presidente del Gobierno contra la Ley de Galicia 11/1993, de 15 de julio, sobre el recurso de casación en materia de Derecho civil especial.

El Tribunal insiste en la idea de que la determinación de las reglas competencia jurisdiccional corresponde en exclusiva al legislador estatal (SSTC 121/1992, de 28 de septiembre, FJ 4; 114/1994, de 14 de abril, FJ 3 b); 91/998, 23 de abril, FJ 3; 173/1998, de 23 de julio, FJ 16), por lo que, sea una mera reiteración de la legislación estatal o, por el contrario, introduzca alguna novedad, carece de competencia el legislador autonómico para promulgarlo, por lo que incurre en inconstitucionalidad. El Tribunal declara inconstitucionales y nulos, por vulnerar el orden constitucional de distribución de competencias, los siguientes preceptos de la mencionada Ley: artículo 1, salvo el apartado letra a) en su inciso final "y cualquiera que sea la cuantía litigiosa", en los términos expuestos en el fundamento jurídico último; artículo 2 en su número 1; artículo 3; artículo 4 y la disposición adicional. Desestima el recurso de inconstitucionalidad en todo lo demás.

La STC 77/2004, de 29 de abril, estimó parcialmente el conflicto positivo de competencia planteado por el Consejo Ejecutivo de la Generalidad de Cataluña contra la Orden del Ministerio de Comercio y Turismo de 6 de febrero de 1996, por la que se regula la concesión de ayudas a las actividades relacionadas en los programas generales del Plan marco de modernización del comercio interior, declarando que son inconstitucionales por vulnerar las competencias de la Generalidad de Cataluña los siguientes preceptos de la Orden del Ministerio de Comercio y Turismo de 6 de febrero de 1996: los apartados tercero, 1; tercero, 3; cuarto 1, en tanto reserva al Ministro la recepción de las solicitudes; cuarto, 2; quinto, 1; sexto, 1, 2 y 3; séptimo; octavo, 2; noveno, sin perjuicio de la legitimidad constitucional del control del Tribunal de Cuentas, y, finalmente, el primer inciso del undécimo, en la medida en que dispone que el procedimiento de gestión presupuestaria aplicable será el de las subvenciones estatales. 
En la STC 98/2004, de 25 de mayo, se dictó una sentencia interpretativa con ocasión del recurso de inconstitucionalidad promovido por el Presidente el Gobierno respecto del artículo 51 y una disposición adicional de la Ley del Parlamento de Canarias 5/1996, de 27 de diciembre, de presupuestos generales de la Comunidad Autónoma para 1997. Concluye el Tribunal que cabe efectuar una interpretación conforme a la Constitución entendiendo que la facultad que atribuye al Gobierno de Canarias el artículo 51.1 de la Ley canaria 5/1996, lo es sólo para fijar precios de referencia, siempre que respeten los mínimos establecidos por la norma básica estatal. Así entendida, la Ley canaria es conforme a la Constitución pues las bases tienen el significado de mínimos a respetar por la legislación autonómica.

La STC 109/2004, de 30 de junio, dictada a resultas de los recursos de inconstitucionalidad promovidos por el Gobierno y el Parlamento de Canarias contra varios preceptos de la Ley 66/1997, de 30 de diciembre, de medidas fiscales, administrativas y del orden social, que modificaron el impuesto sobre la electricidad, estimó parcialmente el recurso planteado por el Parlamento de Canarias, declarando inconstitucional y nulo el apartado 3 de la disposición transitoria decimonovena de la Ley 66/1997.

La STC 157/2004, de 21 de septiembre, resolvió el recurso de inconstitucionalidad interpuesto por el Presidente del Gobierno contra los artículos 23.3, párrafo tercero; $24.1 ; 40.2$ c); $46.1 ; 50.2 ; 72.1$; y la disposición final segunda de la Ley Foral 17/2001, de 12 de julio, reguladora del comercio en Navarra, estimando parcialmente dicho recurso y declarando que los artículos 23.3, párrafo tercero, en el inciso "aplicando para ello en el ámbito de Navarra los porcentajes máximos establecidos en la normativa básica estatal»; 40.2.c), en el inciso "que no podrá ser inferior a dos días consecutivos, ni superior a treinta días»; 46.1, en el inciso "o en unas condiciones especiales que supongan una minoración en relación con el precio practicado habitualmente»; y 50.2, así como la disposición final segunda, son contrarios al orden constitucional de competencias y, por tanto, nulos.

En la STC 158/2004, de 21 de septiembre, se estima parcialmente el conflicto positivo de competencia planteado por el Consejo de Gobierno de la Generalidad de Cataluña contra la Resolución de 25 de julio de 2003, de la Dirección General del Instituto Nacional de Empleo, por la que se prorroga para el curso 2002-2003 la convocatoria de ayudas para permisos individuales de formación del curso 2001-2002 y, en su virtud, se declara que vulneran las competencias de la Generalidad de Cataluña el párrafo primero del artículo único de dicha Resolución de 25 de julio de 2003, en cuanto que prorroga la vigencia de los arts. 6.1; 
$9 ; 10 ; 11 ; 12$, salvo la alusión al Tribunal de Cuentas y su último inciso; 14, segundo párrafo; y disposición adicional primera, apartado 2 de la Resolución de 19 de junio de 2002, de la Dirección General del Instituto Nacional de Empleo, por la que se aprueba la convocatoria de permisos individuales de formación para el curso 2001-2002.

La STC 178/2004, de 21 de octubre, trae causa de las cuestiones de inconstitucionalidad promovidas por la Sección Segunda de la Sala de lo Contencioso-Administrativo del Tribunal Superior de Justicia del País Vasco en relación con el artículo 11 de la Ley del Parlamento Vasco 17/1994, de 30 de junio, de medidas urgentes en materia de vivienda, de tramitación de los instrumentos de planeamiento y gestión urbanística; el artículo 2.2 del Real Decreto-ley 5/1996, de 7 de junio, de medidas liberalizadoras en materia de suelo y de colegios profesionales; el artículo 2.2 de la Ley 7/1997, de 14 de abril, de medidas liberalizadoras en materia de suelo y de colegios profesionales; y el artículo único, apartado 2, de la Ley del Parlamento Vasco 3/1997, de 25 de abril, por la que se determina la participación de la comunidad en las plusvalías generadas por la acción urbanística. En esta sentencia, se estima en parte una de las cuestiones, declarando que son inconstitucionales y, en consecuencia, nulos el artículo 2 del Real Decreto-ley 5/1996 y el artículo 2 de la Ley 7/1997.

La STC 194/2004, de 10 de noviembre, estimó parcialmente los recursos de inconstitucionalidad interpuestos, respectivamente, por el Consejo de Gobierno de la Junta de Andalucía, las Cortes de Aragón y el Gobierno de la Diputación General de Aragón contra la Ley 41/1997, de 5 de noviembre, por la que se modifica la Ley 4/1989, de 27 de marzo, de conservación de los espacios naturales y de la flora y fauna silvestres, y declaró que son inconstitucionales los artículos 19.1, en su inciso "salvo lo establecido en el apartado 3 para los Parques Nacionales", 3, en su inciso "o por la Administración General del Estado en el caso de Parques Nacionales ubicados en el territorio de más de una Comunidad, previo acuerdo favorable de la Comisión Mixta de Gestión encargada de su elaboración", y 7, en su inciso "y autorizado por la Comisión Mixta de Gestión"; 22.3; 23; 23 bis, 3, 5 y 6 c), en su inciso «aprobar los planes sectoriales específicos que le proponga la Comisión Mixta", y g), en su inciso "estableciendo criterios de prioridad"; 23.ter; todos ellos de la Ley 4/1989 en la redacción dada por la Ley 41/1997; y las disposiciones adicionales primera y quinta y disposición final segunda de la Ley 41/1997.

No obstante, dado que la inmediata nulidad de los preceptos declarados inconstitucionales «podría provocar una desprotección medioam- 
biental de la zona con graves perjuicios y perturbaciones a los intereses generales en juego y con afectación de situaciones y actuaciones jurídicas consolidadas", la declaración de inconstitucionalidad de algunos preceptos no lleva aparejada su inmediata declaración de nulidad, la cual se difiere hasta el momento en el que las Comunidades Autónomas regulen las modalidades de gestión de los parques nacionales de su competencia.

Además, el Tribunal declaró que la disposición adicional tercera de la Ley $41 / 1997$ es constitucional dado que el precepto puede ser interpretado en el sentido de que mientras que la ampliación con bienes autonómicos conllevará siempre la iniciativa autonómica, en el supuesto de que la ampliación se realice con bienes estatales o de terceros, la iniciativa podrá ser de la Comunidad o del Ministro de Medio Ambiente, pero que, aún en este caso, no podrá obviarse la conformidad autonómica.

La STC 243/2004, de 16 de diciembre, estimó en parte el recurso de inconstitucionalidad interpuesto por el Presidente del Gobierno contra los artículos 4.1, último inciso, 5, 6 y 7 de la Ley del Parlamento de las Illes Balears 6/1995, de 21 de marzo, de actuación de la Comunidad Autónoma en la aplicación de las medidas judiciales sobre menores infractores, declarando que son inconstitucionales $y$, en consecuencia, nulos: a) El artículo 4.1, último inciso («bien otras medidas enumeradas en el artículo siguiente y tendentes a evitar el proceso»), y el artículo 5. b) Los artículos 6 (a excepción del apartado cuarto y de la segunda frase del apartado quinto, "La Administración autonómica garantizará la idoneidad de los acogedores") y 7.

\section{DERECHOS, DEBERES Y LIBERTADES}

En esta cuestión se podrían clasificar los hechos más relevantes atendiendo a su impronta normativa y a su carácer jurisprudencial.

En primer lugar, y por seguir la ubicación de las materias en el articulado de la Constitución, ha de mencionarse, en materia de extranjería e inmigración, el Real Decreto 2393/2004, de 30 de diciembre, por el que se aprueba el Reglamento de la Ley Orgánica 4/2000, de 11 de enero, sobre derechos y libertades de los extranjeros en España y su integración social (BOE n. ${ }^{\circ} 6$, de 7 de enero de 2005) que, entre otras, cosas, prevé un procedimiento especial para la concesión de autorizaciones de residencia y trabajo.

Previamente se aprobó el Real Decreto 2266/2004, de 3 de diciembre, por el que se modifica el Reglamento de acceso de extranjeros a la condición de militar profesional de tropa y marinería, aprobado por el 
Real Decreto 1244/2002, de 29 de noviembre (BOE n. ${ }^{\circ} 292$, de 4 de diciembre); con la reforma, "el cupo máximo, con vigencia de tres años, de extranjeros en las Fuerzas Armadas con la condición de militar profesional de tropa y marinería será el siete por ciento del total de efectivos de tropa y marinería profesional a que se refiere el apartado 1 del artículo 19 de la Ley 17/1999, de 18 de mayo, de Régimen del Personal de las Fuerzas Armadas".

En este mismo ámbito han de mencionarse las siguientes sentencias del Tribunal Supremo:

La de 10 junio de 2004, de la Sala Tercera, por la que se anula el iniciso "y siempre que mantengan un vínculo de convivencia estable y permanente con estos» del párrafo primero del artículo 2, así como el inciso "y se acredite la convivencia en España al menos durante un año", del número 4 del artículo 11.3.C del Real Decreto 178/2003, de 14 de febrero, sobre entrada y permanencia en España de nacionales de Estados miembros de la Unión Europea y de otros Estados parte en el Acuerdo sobre el Espacio Económico Europeo.

El Tribunal Supremo, en su Sentencia de 26 de julio, de la Sala Segunda, ha realizado también una "relectura» del artículo 89 del Código Penal en lo que respecta a la expulsión automática de los extranjeros condenados a penas de prisión, que no puede realizarse "de forma automática, inmotivada, inaudita parte y sin efectuar el imprescindible juicio de proporcionalidad y ponderación", siendo, por tanto, necesario "el trámite de audiencia al penad y la motivación de la decisión».

La Sentencia de 13 de octubre de 2004, de la Sala Tercera, anuló el inciso «ni tener proceso judicial penal en curso, salvo que el interesado acredite el archivo definitivo de la causa judicial o el sobreseimiento libre de las actuaciones" que se contiene en el n. ${ }^{\circ} 3$ del artículo 1-1 del Real Decreto 239/2000, de 18 de febrero, por el que se establece el procedimiento para la regularización de extranjeros prevista en la disposición transitoria primera de la Ley Orgánica 4/2000, de 11 de enero, sobre derechos y libertades de los extranjeros y su integración social.

Por Sentencia de 21 de octubre de 2004, de la Sala Tercera, se declaró la nulidad de pleno derecho del apartado 5 ("Cuando el empresario o empleador no acredite en su caso, que, con carácter previo, ha cumplido con la obligación de gestionar la oferta ante los servicios públicos de empleo") del artículo 84 Real Decreto 864/2001, de 20 de julio, por el que se aprueba el Reglamento de ejecución de la Ley Orgánica 4/2000, de 11 de enero, sobre Derechos y Libertades de los Extranjeros en España y su integración Social.

Para promover la igualdad, se aprobó, en el ámbito autonómico, la Ley $7 / 2004$, de 16 de julio, gallega para la igualdad de mujeres y hombres (DOG n. ${ }^{\circ} 149$, de 3 de agosto de 2004; BOE n. ${ }^{\circ} 228$, de 21 de septiembre). 
A propósito de la igualdad deben tenerse en cuenta las siguientes sentencias del Tribunal Constitucional: la STC 13/2004, de 9 de febrero, consideró vulnerados los derechos a la igualdad en la aplicación de la ley y a la tutela judicial efectiva a causa de una sentencia contenciosoadministrativa con un fallo diferente a otras dictadas en supuestos idénticos, sin justificar el cambio; la STC 15/2004, de 23 de febrero, apreció vulneración de los derechos a la igualdad y a la tutela judicial efectiva en el caso de una indemnización que aplica los baremos legales sin impedir reparar las lesiones y daños acreditados en el proceso; la STC $27 / 2004$, considera vulnerado el derecho a la igualdad por la fijación en un convenio colectivo de una cuantía diferente por razón de la fecha de ingreso en la empresa; la STC 34/2004, de 8 de marzo, apreció una lesión del derecho a la igualdad por la diferencia retributiva entre trabajadores de la Administración pública en el extranjero, no justificada por razón de la nacionalidad o de una legislación foránea no probada; la STC 107/2004, de 28 de junio, consideró que se habían lesionado los derechos a la igualdad y a la tutela judicial efectiva en las sentencias que desestimaron la solicitud del demandante de personarse como acusador particular en una causa por delito de abuso de autoridad; la estimación del amparo originó una cuestión interna de inconstitucionalidad; en la STC 110/2004, de 30 de junio, estima el Tribunal que las limitaciones presupuestarias no pueden servir para consagrar un régimen retributivo distinto para determinados empleados públicos dependientes de la misma Administración y que ocupan puestos similares; la STC 179/2004, de 18 de octubre, declaró la inconstitucionalidad y consiguiente nulidad del artículo 108, párrafo 2, así como del artículo 127, párrafo 1, de la Ley Orgánica 2/1989, de 13 de abril, procesal militar, en el inciso "excepto cuando ofendido e inculpado sean militares y exista entre ellos relación jerárquica de subordinación"; la STC 161/2004, de 4 de octubre, apreció vulneración del derecho a no ser discriminada por razón del sexo en el caso de suspensión de contrato de trabajo de una pilota de avión a causa de su embarazo, existiendo la posibilidad de un puesto de trabajo en tierra, adecuado a la situación de la demandante y viable en su estado de embarazo; la STC 199/2004, de 14 de noviembre, declaró la vulneración del derecho a la igualdad en un supuesto en el que la denegación de pensión de viudedad se debía a que el matrimonio no había sido inscrito en el Registro Civil.

Respecto a la protección de la vida y la integridad física cabe mencionar la Ley Orgánica 1/2004, de 28 de diciembre, de medidas de protección integral contra la violencia de género (BOE n. ${ }^{\circ} 313$, de 29 de diciembre). 
La Ley se estructura en un título preliminar, cinco títulos, transitorias, una disposición derogatoria y siete disposiciones finales.

En el título preliminar se recogen las disposiciones generales de la Ley que se refieren a su objeto y principios rectores.

En el título I se determinan las medidas de sensibilización, prevención y detección e intervención en diferentes ámbitos. En el educativo se especifican las obligaciones del sistema para la transmisión de valores de respeto a la dignidad de las mujeres y a la igualdad entre hombres y mujeres. En la Educación Secundaria se incorpora la educación sobre la igualdad entre hombres y mujeres y contra la violencia de género como contenido curricular, incorporando en todos los Consejos Escolares un nuevo miembro que impulse medidas educativas a favor de la igualdad y contra la violencia sobre la mujer. En el campo de la publicidad, ésta habrá de respetar la dignidad de las mujeres y su derecho a una imagen no estereotipada, ni discriminatoria, tanto si se exhibe en los medios de comunicación públicos como en los privados. En el ámbito sanitario se contemplan actuaciones de detección precoz y apoyo asistencial a las víctimas, así como la aplicación de protocolos sanitarios ante las agresiones derivadas de la violencia objeto de esta Ley, que se remitirán a los Tribunales correspondientes con objeto de agilizar el procedimiento judicial.

En el título II, relativo a los derechos de las mujeres víctimas de violencia, en su capítulo l, se garantiza el derecho de acceso a la información y a la asistencia social integrada, a través de servicios de atención permanente, urgente y con especialización de prestaciones y multidisciplinariedad profesional. Asimismo, se reconoce el derecho a la asistencia jurídica gratuita, asumiendo una misma dirección letrada su asistencia en todos los procesos. Se extiende la medida a los perjudicados en caso de fallecimiento de la víctima. Se establecen, asimismo, medidas de protección en el ámbito social, modificando el Real Decreto Legislativo $1 / 1995$, de 24 de marzo, por el que se aprueba el texto refundido de la Ley del Estatuto de los Trabajadores, para justificar las ausencias del puesto de trabajo de las víctimas de la violencia de género, posibilitar su movilidad geográfica, la suspensión con reserva del puesto de trabajo y la extinción del contrato. En idéntico sentido se prevén medidas de apoyo a las funcionarias públicas que sufran formas de violencia de las que combate esta Ley, modificando los preceptos correspondientes de la Ley 30/1984, de 2 de agosto, de Medidas para la Reforma de la Función Pública. Se regulan, igualmente, medidas de apoyo económico, modificando el Real Decreto Legislativo 1/1994, de 20 de junio, por el que se aprueba el texto refundido de la Ley General de la Seguridad Social, para que las víctimas de la violencia de género generen derecho a la situación legal de desempleo cuando resuelvan o suspendan voluntariamente su contrato de trabajo.

En el título III, concerniente a la Tutela Institucional, se procede a la creación de dos órganos administrativos. En primer lugar, la Delegación Especial del Gobierno contra la Violencia sobre la Mujer, en el Mi- 
nisterio de Trabajo y Asuntos Sociales, a la que corresponderá, entre otras funciones, proponer la política del Gobierno en relación con la violencia sobre la mujer y coordinar e impulsar todas las actuaciones que se realicen en dicha materia, que necesariamente habrán de comprender todas aquellas actuaciones que hagan efectiva la garantía de los derechos de las mujeres. También se crea el Observatorio Estatal de Violencia sobre la Mujer, como un órgano colegiado en el Ministerio de Trabajo y Asuntos Sociales, y que tendrá como principales funciones servir como centro de análisis de la situación y evolución de la violencia sobre la mujer, así como asesorar y colaborar con el Delegado en la elaboración de propuestas y medidas para erradicar este tipo de violencia.

En su título IV la Ley introduce normas de naturaleza penal, mediante las que se pretende incluir, dentro de los tipos agravados de lesiones, uno específico que incremente la sanción penal cuando la lesión se produzca contra quien sea o haya sido la esposa del autor, o mujer que esté o haya estado ligada a él por una análoga relación de afectividad, aun sin convivencia. También se castigarán como delito las coacciones leves y las amenazas leves de cualquier clase cometidas contra las mujeres mencionadas con anterioridad.

En el título $V$ se establece la llamada Tutela Judicial para garantizar un tratamiento adecuado y eficaz de la situación jurídica, familiar y social de las víctimas de violencia de género en las relaciones intrafamiliares. Conforme a la tradición jurídica española, se ha optado por una fórmula de especialización dentro del orden penal, de los Jueces de Instrucción, creando los Juzgados de Violencia sobre la Mujer, que conocerán de la instrucción, y, en su caso, del fallo de las causas penales en materia de violencia sobre la mujer, así como de aquellas causas civiles relacionadas, de forma que unas y otras en la primera instancia sean objeto de tratamiento procesal ante la misma sede. Respecto de la regulación expresa de las medidas de protección que podrá adoptar el Juez de violencia de género, se ha optado por su inclusión expresa, ya que no están recogidas como medidas cautelares en la Ley de Enjuiciamiento Criminal, que sólo regula la prohibición de residencia y la de acudir a determinado lugar para los delitos recogidos en el artículo 57 del Código Penal (artículo 544 bis LECrim, introducido por la LO 14/1999).

Se contemplan también normas que afectan a las funciones del Ministerio Fiscal, mediante la creación del Fiscal contra la Violencia sobre la Mujer, encargado de la supervisión y coordinación del Ministerio Fiscal en este aspecto, así como mediante la creación de una Sección equivalente en cada Fiscalía de los Tribunales Superiores de Justicia y de las Audiencias Provinciales a las que se adscribirán Fiscales con especialización en la materia. Los Fiscales intervendrán en los procedimientos penales por los hechos constitutivos de delitos o faltas cuya competencia esté atribuida a los Juzgados de Violencia de Género, además de intervenir en los procesos civiles de nulidad, separación o divorcio, o que versen sobre guarda y custodia de los hijos menores en los que se aleguen malos tratos al cónyuge o a los hijos. 
En materia de régimen transitorio se extiende la aplicación de la Ley a los procedimientos en tramitación en el momento de su entrada en vigor, aunque respetando la competencia judicial de los órganos respectivos.

También se aprobaron el Real Decreto 355/2004, de 5 de marzo, por el que se regula el Registro central para la protección de las víctimas de la violencia doméstica (BOE n. ${ }^{\circ} 73$, de 25 de marzo de 2004) y, en la Comunidad Autónoma de Cantabria, la Ley 1/2004, de 1 de abril, integral para la prevención de la violencia contra las mujeres y la protección a sus víctimas (BOC n. ${ }^{\circ} 70$, de 12 de abril; BOE n. ${ }^{\circ} 101$, de 26 de abril).

En otro orden de cosas cabe recordar el Real Decreto Ley 8/2004, de 5 de noviembre, sobre indemnizaciones a los participantes en operaciones internacionales de paz y seguridad (BOE n. ${ }^{\circ} 271$, de 10 de noviembre, corrección de errores en el $\mathrm{BOE} \mathrm{n.}{ }^{\circ} 280$, de 20 de noviembre), convalidado el 2 de diciembre (BOE n. ${ }^{\circ} 298$, de 11 de diciembre); el Real Decreto 1893/2004, de 10 de septiembre, por el que se crea la Comisión Interministerial para el estudio de las víctimas de la guerra civil y del franquismo (BOE n. ${ }^{\circ} 227$, de 20 de septiembre); el Real Decreto 2317/2004, de 17 de diciembre, por el que se crea el Alto Comisionado de Apoyo a las Víctimas del Terrorismo (BOE n. ${ }^{\circ}$ 306, de 21 de diciembre); el Real Decreto 2323/2004, de 17 de diciembre, por el que se nombra Alto Comisionado de Apoyo a las Víctimas del Terrorismo a Gregorio Peces Barba (BOE n. ${ }^{\circ}$ 306, de 21 de diciembre) y, en el ámbito autonómico, la aprobación por las Cortes Valencianas de la Ley 1/2004, de 24 de mayo, de ayuda a las víctimas del terrorismo (DOGV n. ${ }^{\circ} 4762$, de 27 de mayo; BOE n. ${ }^{\circ}$ 157, de 30 de junio).

En materia de libertad ideológica y religiosa destaca la STC 101/2004, de 2 de junio, que consideró vulnerado el derecho a la libertad religiosa de un policía que fue obligado a tomar parte en un acto religioso católico.

Sobre libertad personal y seguridad ha de mencionarse de nuevo la Ley Orgánica 1/2004, de 28 de diciembre, de medidas de protección integral contra la violencia de género (BOE n. ${ }^{\circ} 313$, de 29 de diciembre); también, el Real Decreto Legislativo 8/2004, de 29 de octubre, por el que se aprueba el texto refundido de la Ley sobre responsabilidad civil y seguro en la circulación de vehículos a motor (BOE n. ${ }^{\circ} 267$, de 5 de noviembre); el Real Decreto 1546/2004, de 25 de junio, por el que se aprueba el Plan Básico de Emergencia Nuclear (BOE n. ${ }^{\circ}$ 169, de 14 de julio); el Real Decreto 1598/2004, de 2 de julio, por el que se modifica el Reglamento General de Conductores (BOE n. ${ }^{\circ} 173$, de 19 de julio) y el Real Decreto 1774/2004, de 30 de julio, por el que se aprueba el Regla- 
mento de la Ley Orgánica 5/2000, de 12 de enero, reguladora de la responsabilidad penal de los menores (BOE n. ${ }^{\circ} 209$, de 30 de agosto).

En el ámbito autonómico se aprobó la Ley 1/2004, de 24 de mayo, de modificación del artículo 22 de la Ley 10/1994, de 11 de julio, de la Policía de la Generalidad-Mossos d'Esquadra (DOGC n. ${ }^{\circ} 4142$, de 27 de mayo de 2004)

Deben recordarse las siguientes sentencias del Tribunal Constitucional: la STC 22/2004, de 23 de febrero, declaró vulnerado el derecho a la libertad personal por la prisión provisional mantenida dentro de plazo, pero sin motivación, siendo insuficiente que penda recurso contra la condena de instancia; la STC 23/2004, de 23 de febrero, reconoce la vulneración de este derecho ocasionada por una detención preventiva que duró más del tiempo estrictamente necesario y por la inadmisión a trámite de una petición de habeas corpus por razones de fondo; la STC 81/2004, de 5 de mayo, aprecia vulneración del derecho a la libertad personal una vez que se traspasa el plazo máximo de la prisión provisional en una causa que acumula distintos hechos; las SSTC 120/2004, de 12 de julio, y 155/2004, de 20 de septiembre, estiman vulnerado el derecho con motivo de la prorroga tardía de la prisión provisional a pesar de haberse dictado sentencia condenatoria; la STC 122/2004, de 12 de julio, concluyó que el órgano judicial, al denegar la incoación del procedimiento de habeas corpus con base en consideraciones sobre la legalidad de la situación de privación de libertad de las demandantes de amparo, desconoció la garantía específica del art. 17.4 CE, al anticipar el examen de fondo en el trámite de admisión; la STC 191/2004, de 2 de noviembre, estimó los recursos de amparo respecto de los Autos de un Juzgado y la Sala de lo Penal de la Audiencia Nacional que acordaron la prisión provisional e ingreso en un centro psiquiátrico penitenciario de un inimputable, apreciando que la prisión provisional era injustificada y sin control judicial.

Sobre el derecho al honor destaca la STC 43/2004, de 23 de marzo, que aprecia la vulneración del derecho por un reportaje biográfico en el que se narraba una causa penal ante un consejo de guerra durante la guerra civil, protegido por la libertad científica del historiador.

En lo que al derecho a la intimidad respecta, es importante la STC 196/2004, de 15 de noviembre, que consideró vulnerado el derecho a la intimidad personal de una trabajadora despedida por falta de aptitud debida al uso de drogas, deducida de un reconocimiento médico de empresa no justificado por riesgos laborales ni por el consentimiento de la trabajadora, que no fue informada. La empresa tenía la obligación de informarla expresamente de esa analítica concreta, toda vez que, si 
bien no afectaba a la intimidad corporal, sí tenía como objeto datos sensibles que lo imponían, pues el hecho de haber consumido en algún momento algún género de drogas, pese a que en nuestro ordenamiento es una conducta en sí misma impune, provoca a menudo un juicio social de reproche en sectores significativos de la comunidad. Por ello, los datos mismos que quedaban comprometidos, por su naturaleza, obligaban a una información previa y expresa, tendente a asegurar la libre decisión.

Sobre el derecho a la inviolabilidad de domicilio, la STC 139/2004, de 13 de septiembre, consideró que supone una lesión del derecho fundamental la autorización judicial de entrada para recoger menores desamparados sin motivación. La STC 189/2004, de 2 de noviembre, estimó vulneración del derecho a la inviolabilidad del domicilio por la retirada de prendas y efectos personales de la habitación de una residencia militar sin autorización judicial.

En lo que afecta a la libertad de información y medios de comunicación, se aprobaron el Real Decreto 439/2004, de 12 de marzo por el que se aprueba el plan técnico nacional de la televisión digital local (BOE n. ${ }^{\circ} 85$, de 8 de abril), modificado por el Real Decreto 2268/2004, de 3 de diciembre (BOE n. ${ }^{\circ}$ 292, de 4 de diciembre); el Real Decreto 1319/2004, de 28 de mayo, por el que se concede a la Comunidad Autónoma del Principado de Asturias la gestión directa del tercer canal de televisión (BOE n. ${ }^{\circ}$ 146, de 17 de junio); el Real Decreto 1890/2004, de 10 de septiembre, por el que se concede a la Comunidad Autónoma de Aragón la gestión directa del tercer canal de televisión (BOE n. ${ }^{\circ} 232$, de 25 de septiembre) y el Real Decreto 2296/2004, de 10 de diciembre, por el que se aprueba el Reglamento sobre mercados de comunicaciones electrónicas, acceso a las redes y numeración (BOE n. ${ }^{\circ} 314$, de 30 de diciembre).

En el ámbito autonómico deben mencionarse la Ley 4/2004, de 28 de mayo, de modificación de la Ley $4 / 2000$, de 16 de noviembre, de creación de la Empresa Pública "Corporación Extremeña de Medios Audiovisuales (DOE n. ${ }^{\circ}$ 62, de 1 de junio; BOE n. ${ }^{\circ} 146$, de 17 de junio); la Ley $3 / 2004$, de 28 de junio, de segunda modificación de la Ley $2 / 2000$, de 4 de mayo, del Consejo del Audiovisual de Cataluña (DOGC n..$^{\circ} 4166$, de 2 de junio; $B O E$ n. ${ }^{\circ} 233$, de 27 de septiembre) y la Ley 1/2004, de 14 de diciembre, de creación del Consejo Audiovisual de Cataluña (BOJA n. ${ }^{\circ}$ 254, de 30 de diciembre; BOE n. ${ }^{\circ} 12$, de 14 de enero de 2005).

A propósito de estos derechos han de tenerse en cuenta las siguientes sentencias: la STC 54/2004, de 15 de abril, ampara la noticia que denunció tráfico de influencias en un sumario penal por considerar 
que en su conjunto, incluidos sus titulares, es un reportaje neutral; la STC 56/2004, de 19 de abril, aprecia vulneración parcial del derecho a la libre información, pues no es compatible con la actual legislación reguladora del ejercicio de la libertad de información el establecimiento de una prohibición general con reserva de autorización en cada caso del acceso de medios de captación y difusión de imágenes a las audiencias públicas, porque la utilización de tales medios forma parte del ámbito constitucionalmente protegido por el derecho a la libertad de información que no ha sido limitado con carácter general por el legislador. La eventual limitación o prohibición de tal utilización, inicialmente permitida, ha de realizarse de forma expresa en cada caso por el órgano judicial; la STC 61/2004, de 19 de abril, considera que hay vulneración del derecho a la libre información por la condena de una noticia sobre una denuncia por acoso sexual que se funda en fuentes informativas fiables, aunque luego se demuestre su inexactitud; la STC $65 / 2004$, de 19 de abril, ampara el derecho a la libertad de expresión en el ejercicio de la defensa letrada estimando que las alegaciones orales de un abogado en una vista de apelación que critican con beligerancia la Sentencia impugnada no justifican una sanción de estrados; la STC 115/2004, de 12 de julio, aprecia vulneración de las libertades de expresión e información en la condena penal a una Alcaldesa por emitir un comunicado oficial y realizar declaraciones radiofónicas, denunciando presiones en materia de voto por parte del médico del pueblo; la STC 127/2004, de 19 de julio, estimó que se lesionaba el derecho a la libre expresión con una condena penal pronunciada por expresiones proferidas en una discusión pública, que versa sobre asuntos de interés público y que atañe a personajes públicos; la STC 151/2004, de 20 de septiembre, estima el amparo solicitado por un profesor que resultó despedido tras la publicación de artículo de prensa en el que criticaba a su universidad por su conducta en un conflicto laboral.

La Sala Tercera del Tribunal Supremo, por su parte, dictó la sentencia de 20 de diciembre de 2004 por la que se declara la nulidad de los párrafos 3_ y 4_del apartado 7_ de la Circular 1/1999, de 4 de noviembre, de la Comisión del Mercado de las Telecomunicaciones sobre la implantación de la preasignación de operador por los operadores dominantes en el Mercado de Redes Públicas de Telecomunicaciones Fijas, y la sentencia de 30 de diciembre de 2004 por la que se declara nula de pleno derecho la Orden del Ministerio de Fomento de 9 de octubre de1998, por la que se aprueba el Reglamento Técnico y de Prestación del Servicio de Televisión Digital Terrenal.

En lo que respecta al derecho de asociación, las SSTC 21/2004, $67 / 2004,70 / 2004,80 / 2004,90 / 2004,92 / 2004$ y $141 / 2004$ estiman los re- 
cursos de amparo remitiéndose a la doctrina de la STC 76/2003 sobre la colegiación obligatoria de los funcionarios locales de habilitación nacional.

Sobre el derecho de participación política y de acceso a los cargos públicos representativos, hemos de recordar la Ley Foral 4/2004, de 2 de junio, de modificación del artículo 21 de la Ley Foral 16/1986, de 17 de noviembre, reguladora de las elecciones al Parlamento de Navarra. A partir de su entrada en vigor, "las Administraciones públicas de $\mathrm{Na}$ varra no podrán realizar inauguraciones, ni colocación de primeras piedras durante los treinta días naturales anteriores al día en que se celebren las elecciones" (BON n. ${ }^{\circ}$ 70, de 11 de junio; BOE n. ${ }^{\circ} 170$, de 15 julio), y la Ley $12 / 2004$, de 7 de diciembre, por la que se modifica la Ley 8/1985, de 13 de agosto, de elecciones al Parlamento de Galicia, para trasladar el escrutinio general al octavo día siguiente al de la votación (DOG n. ${ }^{\circ} 243$, de 16 de diciembre; BOE n. ${ }^{\circ} 7$, de 8 de enero de 2005).

En el ámbito jurisprudencial, las Sentencias de la Sala Especial del Tribunal Supremo del artículo 61 de la Ley Orgánica del Poder Judicial, de 21 de mayo de 2004, consideraron que existía una vinculación entre los promotores y de la mitad de los integrantes de la candidatura $\mathrm{He}$ rritarren Zerrenda con la formación ilegalizada Batasuna. El Tribunal Constitucional rechazó los recursos de amparo en la STC 99/2004, de 27 de mayo, reproduciendo la jurisprudencia de la STC 85/2003, de 8 de mayo, sobre la perentoriedad de los recursos electorales y el rechazo razonado de pruebas o de su impugnación; sobre los datos personales de los candidatos y sobre las agrupaciones electorales que de hecho continúan o suceden en la actividad de un partido político ilegal.

Previamente, la STC 26/2004, de 26 de febrero, apreció vulneración del derecho a acceder a los cargos representativos en el rechazo por la Junta Electoral Provincial de Granada a la presentación, dentro del plazo establecido, de una candidatura al Senado por parte de un empleado del servicio de correos, y no personalmente por el representante de la candidatura. Entiende el Tribunal que el más eficaz ejercicio de los derechos de participación democrática consagrados en el artículo 23 autoriza a entender que la presentación puede ser efectuada a través de cualquier mecanismo que permita cumplir los dos presupuestos inexcusables del artículo 45 LOREG.

Las SSTC 226/2004 Y 227/2004, de 29 de noviembre, estimaron los recursos de amparo presentados contra la disolución, en el Parlamento de Galicia, de la Comisión no permanente de investigación de la catástrofe del petrolero «Prestige». En palabras del Tribunal, las normas supletorias recurridas, en la medida en que han introducido una causa de 
disolución no contemplada expresamente por el Reglamento han vulnerado la reserva de Reglamento y afectado, por ello, al derecho garantizado a los parlamentarios recurrentes por el artículo 23.2 de la Constitución en orden al ejercicio de sus funciones representativas en condiciones de igualdad y con arreglo a lo previsto en el Reglamento del Parlamento de Galicia. Procede, por tanto, decretar su nulidad, que por consecuencia debe extenderse al Acuerdo del Pleno del Parlamento de 11 de marzo de 2003, que les dio cumplida aplicación al caso que ha motivado las presentes demandas de amparo.

Sobre el acceso a las funciones públicas, en la STC 221/2004, de 29 de noviembre, el Tribunal estimó que el régimen legal del procedimiento de libre designación no justifica que unos destinos se adjudiquen sin previa publicidad.

En materia de tutela judicial debe recordarse de nuevo la Ley Orgánica $1 / 2004$, de 28 de diciembre, de medidas de protección integral contra la violencia de género ( $\mathrm{BOE}$ n. ${ }^{\circ} 313$, de 29 de diciembre).

En su título $\mathrm{V}$ establece la Ilamada Tutela Judicial para garantizar un tratamiento adecuado y eficaz de la situación jurídica, familiar y social de las víctimas de violencia de género en las relaciones intrafamiliares. Conforme a la tradición jurídica española, se ha optado por una fórmula de especialización dentro del orden penal, de los Jueces de Instrucción, creando los Juzgados de Violencia sobre la Mujer, que conocerán de la instrucción, y, en su caso, del fallo de las causas penales en materia de violencia sobre la mujer, así como de aquellas causas civiles relacionadas, de forma que unas y otras en la primera instancia sean objeto de tratamiento procesal ante la misma sede. Respecto de la regulación expresa de las medidas de protección que podrá adoptar el Juez de violencia de género, se ha optado por su inclusión expresa, ya que no están recogidas como medidas cautelares en la Ley de Enjuiciamiento Criminal, que sólo regula la prohibición de residencia y la de acudir a determinado lugar para los delitos recogidos en el artículo 57 del Código Penal (artículo 544 bis LECrim, introducido por la LO 14/1999).

Se contemplan también normas que afectan a las funciones del Ministerio Fiscal, mediante la creación del Fiscal contra la Violencia sobre la Mujer, encargado de la supervisión y coordinación del Ministerio Fiscal en este aspecto, así como mediante la creación de una Sección equivalente en cada Fiscalía de los Tribunales Superiores de Justicia y de las Audiencias Provinciales a las que se adscribirán Fiscales con especialización en la materia. Los Fiscales intervendrán en los procedimientos penales por los hechos constitutivos de delitos o faltas cuya competencia esté atribuida a los Juzgados de Violencia de Género, además de intervenir en los procesos civiles de nulidad, separación o divorcio, o que versen sobre guarda y custodia de los hijos menores en los que se aleguen malos tratos al cónyuge o a los hijos. 
En materia de régimen transitorio se extiende la aplicación de la Ley a los procedimientos en tramitación en el momento de su entrada en vigor, aunque respetando la competencia judicial de los órganos respectivos.

En cuanto a las numerosas sentencias del Tribunal Constitucional que se han pronunciado sobre alguno de los derechos protegidos por el artículo 24 de la Constitución, han de citarse las siguientes, agrupadas por el concreto derecho amparado,

Sobre el derecho de acceso a la justicia, la STC 45/2004, de 23 de marzo, estimó la legitimación activa de un colegio profesional para impugnar disposiciones reglamentarias en interés de la profesión; la STC 73/2004, de 22 de abril, ampara la legitimación activa de una asociación de consumidores para defender a sus miembros, en un contencioso tributario que afectaba a sus intereses como consumidores o usuarios; la STC 112/2004, de 12 de julio, resuelve que se lesiona el derecho a la tutela judicial efectiva en su vertiente de acceso a la justicia con la inadmisión de un recurso contencioso-administrativo por falta de legitimación de un sindicato, ignorando su legítimo interés profesional o económico (en el mismo sentido, STC 142/2004, de 13 de septiembre); la STC $179 / 2004$ considera contraria a los derechos a la igualdad y a la tutela judicial efectiva la prohibición de que los militares ejerzan la acusación particular y la acción civil cuando existe con el inculpado una relación jerárquica de subordinación; la STC 93/2004, de 24 de mayo estima que hay lesión del derecho en la prescripción de una acción civil apreciada sin tomar en cuenta que el archivo de las previas diligencias penales no fue notificado al perjudicado; la STC 126/2004, de 19 de julio considera que se vulnera este derecho por la inadmisión de demanda laboral por extemporánea, aplicando el plazo de un procedimiento especial cuyos requisitos no fueron cumplidos por la contraparte; la STC 154/2004, de 20 de septiembre, declara lesionado el derecho por la inadmisión de demanda social por caducidad, a pesar de haber sido interpuesta tras ser devuelta por la jurisdicción contencioso-administrativa indicada erróneamente por la Administración; la STC 173/2004, de 18 de octubre, declara la legitimación activa de los concejales que no han votado en contra de acuerdos municipales porque no pertenecen al órgano competente; lesiona el derecho de acceso a la justicia, como declara la STC 251/2004, de 20 de diciembre, la inadmisión de un recurso contencioso-administrativo por extemporáneo, incurriendo en un error patente, porque había sido presentado en el Juzgado de guardia el día anterior; de acuerdo con la STC 252/2004, de 20 de diciembre, es reprochable la inadmisión de una demanda social por caducidad, al haber transcurrido el plazo legal, a pesar de haber sido interpuesta dentro del plazo indicado erróneamente por la Administración.

Sobre el derecho a un proceso con todas las garantías, la STC 9/2004, de 9 de febrero, reconoce que se lesiona por la condena basada en un in- 
forme pericial sobre la valoración del animal muerto no sometido a contradicción en el proceso penal; la STC 10/2004, de 9 de febrero admite que hay contravención en la condena pronunciada en apelación sin haber celebrado vista pública; en el mismo sentido se manifiesta la STC 50/2004, de 30 de marzo; la STC 58/2004, de 19 de abril, estimó que se había lesionado el derecho a la tutela judicial efectiva sin indefensión y a un proceso con garantías por una sentencia no fundada en Derecho porque inaplica una ley autonómica vigente, que establece un recargo tributario, sin plantear cuestión de inconstitucionalidad ni cuestión prejudicial de Derecho comunitario europeo; la STC 75/2004, de 26 de abril, estimó que se produjo lesión del derecho a un proceso con garantías y parcial del derecho a la presunción de inocencia en la condena pronunciada en apelación sin haber celebrado vista pública; en el mismo sentido, SSTC 94/2004, 95/2004 y 96/2004, todas de 24 de mayo, y las SSTC 128 y $200 / 2004$, de 19 de julio y 15 de noviembre.

A propósito del derecho a la defensa y la prohibición de indefensión, la STC 71/2004, de 19 de abril, considera que lo vulnera la resolución sobre guarda de una menor en ejecución de un Auto dictado diecinueve meses antes, que había acordado el cese de su acogimiento por desamparo y denegado su carácter preadoptivo, sin valorar el riesgo para su salud psíquica por nuevas circunstancias, y sin oírla personalmente; la STC 145/2004, de 13 de septiembre, lo estima lesionado en el procedimiento administrativo sancionador por el emplazamiento edictal de la empresa titular del vehículo infractor; la STC 162/2004, de 4 de octubre, repara la lesión originada por un emplazamiento edictal sin tomar en cuenta el cambio de domicilio social inscrito en el Registro Mercantil, ni el domicilio particular de la avalista de la póliza de crédito, y la STC 225/2004, de 29 de noviembre, frente a un emplazamiento edictal en proceso civil, tras intentar el personal en una dirección errónea indicada en la demanda; finalmente, la STC 203/2004, de 16 de noviembre, condena la inadmisión de demanda social tras requerir que se subsane su contenido en términos minuciosos o jurídicos de fondo.

En materia de derecho a la prueba, la STC 52/2004, de 13 de abril, lo considera vulnerado en la denegación del testimonio de otros reclusos decisivo en términos de defensa; la STC 88/2004, de 10 de mayo, en la sentencia contencioso-administrativa que desestima la demanda por falta de prueba, tras haber denegado el recibimiento a prueba del pleito; la STC 91/2004, de 19 de mayo, estima lesionado el derecho al proceso con garantías y los derechos a la prueba y a la tutela judicial efectiva con la denegación arbitraria de la prueba solicitada por el preso para contradecir el parte del funcionario; la STC 100/2004, de 2 de junio, lo aprecia lesionado en la desestimación de demanda contra un sanción administrativa con una motivación inadecuada; la STC 148/2004, estima la contravención de los derechos a la tutela judicial y a un proceso con garantías en relación con la prueba por la extradición pasiva para ser enjuiciado por asesinato sin indagar sobre las alegaciones de persecución política; la STC 247/2004, de 20 de diciembre, aprecia una lesión en 
la sentencia contencioso-administrativa que desestima la demanda por falta de prueba, tras haber quedado sin practicarse las admitidas sobre la alegada desviación de poder cometida por la Administración.

En lo que afecta al derecho a la presunción de inocencia, la STC $17 / 2004$, de 23 de febrero, apreció que se lesiona en una condena penal fundada en declaraciones de una coimputada rebelde, no corroboradas (en el mismo sentido, STC 118/2004, de 12 de julio); en la STC 68/2004, de 19 de abril, por una condena fundada en una prueba de alcoholemia que no acredita todos los elementos fácticos del delito; la STC 147/2004, de 13 de septiembre, aprecia la lesión parcial del derecho a la presunción de inocencia por la condena fundada en declaraciones de un coimputado, corroboradas en uno de los dos atracos encausados; la STC 152/2004, de 20 de septiembre, repara la vulneración del derecho a la presunción de inocencia producida en una condena penal fundada en declaraciones de unos coimputados, no corroboradas aunque sean coincidentes.

Respecto al derecho al juez legal, la STC 131/2004, de 19 de julio, estima lesionados los derechos a la tutela judicial efectiva sin indefensión y al juez legal por la anulación del sobreseimiento de una causa penal, para que el antiguo titular del Juzgado dicte Auto calificando los hechos como falta.

Sobre la imparcialidad judicial, la STC 39/2004, de 22 de marzo, estima los recursos de amparo promovidos por los condenados por una Sala de enjuiciamiento formada por los mismos Magistrados que habían revocado el archivo de la causa, mediante Auto que exteriorizaba un juicio anticipado;

En lo que respecta al derecho a los recursos, la STC 114/2004, de 12 de julio, declara quebrantado el derecho con la devolución de un escrito, por parte de un Presidente de Audiencia, que carece de cobertura en la legislación procesal e implica la privación irrazonable de un recurso de queja; la STC 187/2004, de 2 de noviembre, repara la inadmisión del recurso de casación por solicitud inadecuada de nombramiento de Abogado y Procurador de oficio, sin ofrecer subsanación o alternativa alguna.

Sobre el derecho a un proceso sin dilaciones indebidas, la STC 160/2004, de 4 de octubre, condena el traslado de las actuaciones a las acusaciones sucesivamente, y con un retraso superior a trece meses; en la STC 166/2004, de 4 de octubre, se declara la contravención del derecho por causa de unos litigios demorados casi tres años, tras haber levantado la suspensión que había sido acordada durante ocho años por prejudicialidad penal.

En cuanto afecta a la inmodificabilidad de las resoluciones judiciales firmes, la STC 76/2004, de 26 de abril, aprecia vulneración parcial del derecho en la revisión de penas irrazonable por no atender a las redenciones de pena por el trabajo consolidadas; la STC 89/2004, de 19 de mayo, estima que vulnera el derecho a la tutela judicial efectiva la alteración de la cuantía de la indemnización otorgada en una sentencia firme para aplicar una reforma legal de los baremos de daños. 
Sobre la congruencia procesal, la STC 130 de 19 de julio, aprecia incongruencia en la aceptación de desistimiento, con costas procesales, cuando se había solicitado la terminación del recurso por carencia sobrevenida de objeto, sin ellas; es incongruente, según la STC 250/2004, la sentencia civil que resuelve por un fundamento ajeno a los motivos del recurso de apelación.

A propósito del cumplimiento de las resoluciones judiciales, la STC 223/2004, de 29 de noviembre, ampara la pensión compensatoria por separación matrimonial dejada sin efecto en virtud de sentencia de divorcio que no se pronunció sobre ella.

Sobre los errores lesivos de la tutela judicial, la STC 176/2004, de 18 de octubre, aprecia vulneración del derecho a la tutela judicial efectiva en la sentencia civil que desestima parcialmente una demanda por no haber alegado incumplimiento contractual, sino solamente vicios de la construcción, con error patente; la STC 201/2004, de 15 de noviembre, concede el amparo frente a una sentencia de suplicación que incurre en error patente, porque la inadmisión de la prueba sí había dado lugar a protesta de la defensa, aunque constara en diligencia adicional al acta del juicio; finalmente, atenta contra el derecho a la tutela judicial efectiva, según la STC 249/2004, de 20 de diciembre, la no subsanación de un error de identificación irrelevante en la impugnación de honorarios de un abogado.

A propósito de la legalidad penal ha de citarse la Ley Orgánica $1 / 2004$, de 28 de diciembre, de medidas de protección integral contra la violencia de género (BOE n. ${ }^{\circ} 313$, de 29 de diciembre).

En su título IV, la Ley introduce normas de naturaleza penal, mediante las que se pretende incluir, dentro de los tipos agravados de lesiones, uno específico que incremente la sanción penal cuando la lesión se produzca contra quien sea o haya sido la esposa del autor, o mujer que esté o haya estado ligada a él por una análoga relación de afectividad, aun sin convivencia. También se castigarán como delito las coacciones leves y las amenazas leves de cualquier clase cometidas contra las mujeres mencionadas con anterioridad.

Son también relevantes el Real Decreto 1774/2004, de 30 de julio, por el que se aprueba el Reglamento de la Ley Orgánica 5/2000, de 12 de enero, reguladora de la responsabilidad penal de los menores (BOE n. ${ }^{\circ} 209$, de 30 de agosto) y la Ley 3/2004, de 10 de diciembre, de creación de la Agencia de la Comunidad de Madrid para la reeducación y reinserción del menor infractor (BOCM n. ${ }^{\circ}$ 297, de 14 de diciembre; BOE n. ${ }^{\circ} 42$, de 18 de febrero de 2005).

Han de reseñarse las siguientes sentencias:

la STC 25/2004, de 26 de febrero, ampara el derecho frente a una infracción administrativa que carece de cobertura legal, no siendo sufi- 
ciente la ordenanza municipal ni la Ley de protección de la seguridad ciudadana; la STC 111/2004, de 12 de julio, declara, ante la sentencia que confirmó la multa impuesta por no haber aportado datos suficientes para identificar al conductor de un vehículo que había cometido una infracción de tráfico, que la sanción administrativa carece de fundamento razonable en la infracción administrativa aplicada; en el mismo sentido se pronuncia la STC 138/2004, de 13 de septiembre, en un caso de sanción por una falta de coacciones al anunciar una huelga de hambre, entendiendo que la sanción penitenciaria carece de fundamento razonable en la infracción administrativa aplicada.

También la Sentencia de 27 de octubre de 2004, de la Sala Tercera del Tribunal Supremo, por la que se declara nulo de pleno derecho el apartado 2, párrafo segundo, del artículo 12 del Reglamento de procedimiento sancionador en materia de tráfico, circulación de vehículos a motor y seguridad vial según modificación operada por Real Decreto $318 / 2003$, de 14 de marzo, que dispone: "La resolución que se dicte lo será por el importe total de la multa que proceda imponer y tendrá en cuenta el pago anticipado que se hubiera efectuado con anterioridad a los efectos previstos en el artículo 77.2 del texto articulado de la Ley sobre Tráfico, Circulación de Vehículos a Motor y Seguridad Vial, en cuanto se refiere a la terminación del procedimiento. En todo caso, el importe total de la multa impuesta podrá ser objeto de impugnación en el correspondiente recurso que se formule, cuya resolución no quedará vinculada por el pago anticipadamente realizado", por vulnerar lo dispuesto en los artículos 67.1, párrafo segundo, y 77.2 del Texto articulado de la Ley sobre Tráfico, Circulación de Vehículos a Motor y Seguridad Vial, aprobado por Real Decreto Legislativo 339/1990, de 2 de marzo, reformado por Ley 19/2001, de 19 de diciembre.

Sobre el derecho a la educación, han de citarse, respecto a la enseñanza no universitaria, el Real Decreto 1318/2004, de 28 de mayo, por el que se modifica el Real Decreto 827/2003, de 27 de junio, por el que se establece el calendario de aplicación de la nueva ordenación del sistema educativo, establecida por la Ley Orgánica 10/2002, de 23 de diciembre, de Calidad de la Educación (BOE n. ${ }^{\circ} 130$, de 29 de mayo); el Real Decreto 1936/2004, de 27 de septiembre, por el que se modifica el Real Decreto 631/1993, de 3 de mayo, por el que se regula el Plan nacional de formación e inserción profesional (BOE n. ${ }^{\circ} 238$, de 2 de octubre de 2004) y el Real Decreto 1472/2004, de 18 de junio, por el que se amplía el plazo señalado en la disposición adicional segunda del Real Decreto 1538/2003, de 5 de diciembre, por el que se establecen las especialidades básicas de inspección educativa (BOE n. ${ }^{\circ} 148$ de 19 de junio); en el ámbito autonómico se aprobó la Ley 3/2004, de 25 de junio, de Consejos Escolares de La Rioja (BOLR n. ${ }^{\circ} 83$, de 1 de julio; BOE n. ${ }^{\circ}$ 169 , de 14 de julio). 
A propósito de la enseñanza superior, universitaria e investigación, cabe citar el Real Decreto 2132/2004, de 29 de octubre, por el que se establecen los requisitos y procedimientos para solicitar el desarrollo de proyectos de investigación con células troncales obtenidas de preembriones sobrantes (BOE n. ${ }^{\circ} 262$, de 30 de octubre) y, en la Comunidad Valenciana, la Ley 6/2004, de 13 de julio, de modificación de la Ley $5 / 2002$, de 19 de junio, de creación del Consejo Valenciano de Universidades y de la Comisión Valenciana de acreditación y evaluación de la calidad en el sistema universitario valenciano (DOGV n. ${ }^{\circ} 4797$, de 14 de julio; $\mathrm{BOE}$ n. ${ }^{\circ} 188$, de 5 de agosto).

En el ámbito jurisprudencial, la sentencia de 20 de octubre de 2004, de la Sala Tercera del Tribunal Supremo, anula los artículos 3.4 en relación con el anexo III y el artículo 5.1A del Real Decreto 774/2002, de 26 de julio, por el que se regula el sistema de habilitación nacional para el acceso a Cuerpos de funcionarios docentes universitarios y el régimen de los concursos de acceso respectivos, en especial, los artículos 3.4 en relación con el anexo III y el artículo $5.1 \mathrm{~A}$ del Real Decreto, en relación con el anexo IV.

Por lo que respecta a la libertad sindical, han de tenerse en cuenta estas sentencias: las SSTC 36/2004, de 8 de marzo, 103/2004, de 2 de junio, y 175/2004, de 18 de octubre, amparan la facultad de los sindicatos más representativos para promover elecciones de delegados de personal en empresas pequeñas. La STC 7/2004, de 5 de mayo, aprecia indicios racionales de discriminación al cesar a un representante sindical de un puesto de libre designación y la STC 188/2004, de 2 de noviembre, indicios racionales de marginación laboral de trabajadores por su condición de representantes sindicales, con ocasión de una reorganización de la empresa; finalmente, la STC 198/2004, de 15 de noviembre, considera lesionado este derecho con el despido de un delegado sindical por distribuir anuncios en prensa y comunicados a clientes de la empresa hotelera, criticándola y anunciando movilizaciones.

En cuestiones tributarias han de citarse el Real Decreto legislativo $2 / 2004$, de 5 de marzo, por el que se aprueba el texto refundido de la Ley Reguladora de las Haciendas Locales (BOE n. ${ }^{\circ} 59$, de 9 de marzo, corrección de errores en el BOE n. ${ }^{\circ} 63$, de 13 de marzo); el Real Decreto legislativo 3/2004, de 5 de marzo, por el que se aprueba el texto refundido de la Ley del Impuesto sobre la Renta de las Personas Físicas (BOE n. ${ }^{\circ}$ 60, de 10 de marzo, corrección de errores en el BOE n. ${ }^{\circ} 61$, de 11 de marzo); el Real Decreto legislativo 4/2004, de 5 de marzo, por el que se aprueba el texto refundido de la Ley del Impuesto sobre Sociedades (BOE n. ${ }^{\circ}$ 61, de 15 de marzo); y el Real Decreto legislativo 5/2004, 
de 5 de marzo, por el que se aprueba el texto refundido de la Ley del Impuesto sobre la Renta de no residentes (BOE n. ${ }^{\circ} 62$, de 12 de marzo).

En el ámbito reglamentario se aprobaron el Real Decreto 1775/2004, de 30 de julio, por el que se aprueba el Reglamento del Impuesto sobre la Renta de las Personas Físicas (BOE $n .{ }^{\circ} 187$, de 4 de agosto) y el Real Decreto 2347/2004, de 23 de diciembre, por el que se modifica el Reglamento del Impuesto sobre la Renta de las Personas Físicas, aprobado por el Real Decreto 1775/2004, de 30 de julio, en materia de salario medio anual del conjunto de contribuyentes y de retenciones e ingresos a cuenta sobre rendimientos del trabajo (BOE n. ${ }^{\circ} 309$, de 24 de diciembre).

Una vez aprobado el Real Decreto Legislativo 5/2004, de 5 de marzo, de la Ley del Impuesto sobre la Renta de no Residentes se procedió a refundir todas las disposiciones reglamentarias vigentes en la materia, lo que se hizo por el Real Decreto 1776/2004, de 30 de julio, por el que se aprueba el Reglamento del Impuesto sobre la Renta de no Residentes (BOE n. ${ }^{\circ} 188$, de 5 de agosto).

Tras la aprobación del Real Decreto Legislativo 4/2004, de 5 de marzo, de la Ley de Impuesto sobre Sociedades, se procedió a refundir todas las disposiciones reglamentarias vigentes en la materia por medio del Real Decreto 1777/2004, de 30 de julio, por el que se aprueba el Reglamento del Impuesto sobre Sociedades (BOE n. ${ }^{\circ} 189$, de 6 de agosto).

Finalmente, ha de reseñarse la aprobación del Real Decreto 1408/2004, de 11 de junio, por el que se modifica el Real Decreto 1326/1987, de 11 de septiembre, por el que se establece el procedimiento de aplicación de las directivas de la Comunidad Económica Europea sobre intercambio de información tributaria (BOE n. ${ }^{\circ} 153$, de 25 de junio); del Real Decreto 1178/2004, de 30 de julio, por el que se establecen obligaciones de información respecto de las participaciones preferentes y otros instrumentos de deuda y de determinadas rentas obtenidas por personas físicas residentes en la Unión Europea (BOE n. ${ }^{\circ}$ 190, de 7 de agosto) y del Real Decreto 2063/2004, de 15 de octubre, por el que se aprueba el Reglamento general del régimen sancionador tributario (BOE n. ${ }^{\circ} 260$, de 28 de octubre).

En el ámbito autonómico, y para surtir efectos en el año 2005, se aprobaron las siguientes Leyes:

en Andalucía la Ley 3/2004, de 28 de diciembre, de medidas tributarias, administrativas y financieras (BOJA n. ${ }^{\circ} 251$, de 31 de diciembre de 2004; BOE n. ${ }^{\circ}$ 18, de 21 de enero de 2005); en Aragón la Ley 12/2004, de 29 de diciembre, de medidas tributarias y administrativas (BOA n. ${ }^{\circ} 153$, de 31 de diciembre de 2004; BOE n. ${ }^{\circ}$ 42, de 18 de febrero de 2005); en As- 
turias la Ley 6/2004, de 28 de diciembre, de acompañamiento a los Presupuestos Generales para 2005 (BOPA n. ${ }^{\circ} 302$, de 31 de diciembre de 2004; BOE n. ${ }^{\circ} 32$, de 7 de febrero de 2005); en Illes Balears la Ley 8/2004, de 23 de diciembre, de medidas tributarias, administrativas y de función pública (BOIB n. ${ }^{\circ}$ 188, de 30 de diciembre de 2004; BOE n. ${ }^{\circ} 16$, de 19 de enero); en Cantabria la Ley $7 / 2004$, de 27 de diciembre, de medidas administrativas y fiscales (BOC n. ${ }^{\circ} 252$, de 31 de diciembre de 2004; BOE n. ${ }^{\circ}$ 17, de 20 de enero de 2005); en Castilla y León la Ley 9/2004, de 28 de diciembre, medidas económicas, fiscales y administrativas (BOCL suplemento al n. ${ }^{\circ} 252$, de 31 de diciembre; BOE n. ${ }^{\circ} 21$, de 25 de enero de 2005); en Cataluña la Ley 12/2004, de 27 de diciembre, de medidas financieras (DOGC n. ${ }^{\circ} 4292$, de 31 de diciembre; BOE n. ${ }^{\circ} 41$, de 17 de febrero de 2005; en Galicia la Ley 14/2004, de 29 diciembre, de medidas tributarias y de régimen administrativo (DOG $n .{ }^{\circ} 253$, de 30 de diciembre de 2004; BOE n. ${ }^{\circ} 29$, de 3 de febrero de 2005); en La Rioja la Ley 9/2004, de 22 de diciembre, de medidas fiscales y administrativas para el año 2005 (BOLR n. ${ }^{\circ}$ 167, de 30 de diciembre de 2004; BOE n. ${ }^{\circ} 10$, de 12 de enero de 2005); en la Comunidad de Madrid la Ley 5/2004, de 28 de diciembre, de medidas fiscales y administrativas (BOCM n. ${ }^{\circ} 310$, de 30 de diciembre de 2004, BOE n. ${ }^{\circ} 42$, de 18 de febrero de 2005); en Navarra la Ley Foral 19/2004, de 29 de diciembre, de modificación de diversos impuestos y otras medidas tributarias (BON n. ${ }^{\circ} 157$, de 31 de diciembre de 2004; BOE n. ${ }^{\circ} 27$, de 12 de febrero de 2005) y en la Comunidad Valenciana la Ley 12/2004, de 17 de diciembre, de medidas fiscales, de gestión administrativa y financiera, y de organización de la Generalitat Valenciana (DOGV n. ${ }^{\circ}$ 41913, de 29 de diciembre de 2004; BOE n. ${ }^{\circ} 38$, de 14 de febrero de 2005).

Ha de citarse también la Ley Foral 1/2004, de 17 de febrero, por la que se da nueva redacción al artículo 67 bis de la Ley Foral 22/1998, de 30 de diciembre, del Impuesto sobre la Renta de las Personas Físicas, que regula la deducción por pensiones de viudedad (BON n. ${ }^{\circ} 22$, de 20 de febrero; BOE n. ${ }^{\circ} 152$, de 24 de junio).

En cuanto al derecho de propiedad, han de citarse el Real Decreto legislativo 1/2004, de 5 de marzo, por el que se aprueba el texto refundido de la Ley del Catastro Inmobiliario (BOE n. ${ }^{\circ} 58$, de 8 de marzo) y el Real Decreto 1937/2004, de 27 de septiembre, por el que se aprueba el Reglamento de ejecución de la Ley 20/2003, de 7 de julio, de Protección Jurídica del Diseño Industrial (BOE n. ${ }^{\circ} 250$, de 16 de octubre).

En el ámbito autonómico, la Ley de Aragón 6/2004, de 9 de diciembre, por la que se establecen medidas en materia de expropiación forzosa para actuaciones de mejora y creación de regadíos (BOA n. ${ }^{\circ}$ 150, de 24 de diciembre; BOE n. ${ }^{\circ}$ 36, de 11 de febrero de 2005).

En materia de empleo y trabajo, debe mencionarse, en cuanto a la normativa estatal, el Real Decreto-Ley 3/2004, de 25 de junio, para la ra- 
cionalización de la regulación del salario mínimo interprofesional y para el incremento de su cuantía (BOE n. ${ }^{\circ} 154$, de 26 de junio), convalidado el 21 de julio (BOE n. ${ }^{\circ}$ 178, de 24 de julio); el Real Decreto $1595 / 2004$, de 2 de julio, por el que se modifica el Real Decreto 1879/1996, de 2 de agosto, por el que se regula la composición de la Comisión Nacional de Seguridad y Salud en el Trabajo (BOE n. ${ }^{\circ} 160$, de 3 de julio) y el Real Decreto 1936/2004, de 27 de septiembre, por el que se modifica el Real Decreto 631/1993, de 3 de mayo, por el que se regula el Plan nacional de formación e inserción profesional (BOE n. ${ }^{\circ}$ 238, de 2 de octubre de 2004).

También se aprobó la Ley $2 / 2004$, de la Comunidad Valenciana, de 28 de mayo, de creación del Instituto Valenciano de seguridad y salud en el trabajo (DOGV n. ${ }^{\circ} 4765$, de 1 de junio; BOE n. ${ }^{\circ} 157$, de 30 de junio).

A propósito de la libertad de empresa y economía de mercado se aprobaron el Real Decreto 2295/2004, de 10 de diciembre, relativo a la aplicación en España de las normas comunitarias de competencia (BOE n. ${ }^{\circ} 308$, de 23 de diciembre) y, en las Comunidades Autónomas, la Ley 6/2004, de 12 de julio, reguladora de los Órganos de Defensa de la Competencia de la Comunidad Autónoma de Galicia (DOG n. ${ }^{\circ}$ 141, de 22 de julio; BOE n. ${ }^{\circ} 201$, de 20 de agosto); en las Illes Balears, la Ley $6 / 2004$, de 23 de diciembre, de modificación de la Ley 5/2002, de 21 de junio, de subvenciones (BOIB n. ${ }^{\circ} 186$, de 30 de diciembre; BOE n. ${ }^{\circ} 16$, de 19 de enero de 2005) y la Ley 6/2004, de 28 de diciembre, de creación del Tribunal de Defensa de la Competencia de la Comunidad de Madrid (BOCM n. ${ }^{\circ}$ 310, de 30 de diciembre; BOE n. ${ }^{\circ} 42$, de 18 de febrero de 2005).

Sobre prestaciones de carácter social cabe citar, nuevamente, la Ley Orgánica 1/2004, de 28 de diciembre, de medidas de protección integral contra la violencia de género (BOE n. ${ }^{\circ} 313$, de 29 de diciembre).

En el título II, relativo a los derechos de las mujeres víctimas de violencia, en su capítulo l, se garantiza el derecho de acceso a la información y a la asistencia social integrada, a través de servicios de atención permanente, urgente y con especialización de prestaciones y multidisciplinariedad profesional. Asimismo, se reconoce el derecho a la asistencia jurídica gratuita, asumiendo una misma dirección letrada su asistencia en todos los procesos. Se extiende la medida a los perjudicados en caso de fallecimiento de la víctima. Se establecen, asimismo, medidas de protección en el ámbito social, modificando el Real Decreto Legislativo 1/1995, de 24 de marzo, por el que se aprueba el texto refundido de la Ley del Estatuto de los Trabajadores, para justificar las ausencias del puesto de trabajo de las víctimas de la violencia de género, posibilitar su 
movilidad geográfica, la suspensión con reserva del puesto de trabajo y la extinción del contrato. En idéntico sentido se prevén medidas de apoyo a las funcionarias públicas que sufran formas de violencia de las que combate esta Ley, modificando los preceptos correspondientes de la Ley 30/1984, de 2 de agosto, de Medidas para la Reforma de la Función Pública. Se regulan, igualmente, medidas de apoyo económico, modificando el Real Decreto Legislativo 1/1994, de 20 de junio, por el que se aprueba el texto refundido de la Ley General de la Seguridad Social, para que las víctimas de la violencia de género generen derecho a la situación legal de desempleo cuando resuelvan o suspendan voluntariamente su contrato de trabajo.

También se aprobó, en Galicia, la Ley 16/2004, de 29 de diciembre, por la que se modifica la Ley 9/1991, de 2 de octubre, de medidas básicas para la inserción social (DOG n. ${ }^{\circ} 254$, de 31 de diciembre; BOE n. ${ }^{\circ}$ 29, de 3 de febrero de 2005).

Para la protección de la familia se aprobó, en Aragón, la Ley 2/2004, de modificación de la Ley 6/1999, de 26 de marzo, relativa a parejas estables no casadas, que así podrán adoptar conjuntamente (BOA n. ${ }^{\circ} 54$, de 12 de mayo); en Cataluña, cabe citar la Ley 5/2004, de 9 de julio, de creación de guarderías de calidad (BOE n. ${ }^{\circ} 233$, de 27 de septiembre).

En materia de Seguridad Social y jubilación cabe citar el Real Decreto-Ley 10/2004, de 23 de diciembre, por el que se amplía el plazo de adaptación de las comisiones de control de los planes de pensiones de empleo (BOE n. ${ }^{\circ} 312$, de 28 de diciembre), convalidado el 28 de diciembre (BOE n. ${ }^{\circ} 11$, de 13 de enero de 2005) y el Real Decreto-Ley $11 / 2004$, de 23 de diciembre, por el que se modifica, en materia de pensiones públicas, la Ley de Presupuestos Generales del Estado para el año 2005 (BOE n. ${ }^{\circ} 312$, de 28 de diciembre de 2004), convalidado el 28 de diciembre (BOE n. ${ }^{\circ} 11$, de 13 de enero de 2005).

Además, el Real Decreto 1415/2004, de 11 de junio, por el que se aprueba el Reglamento General de recaudación de la Seguridad Social (BOE n. ${ }^{\circ}$ 153, de 25 de junio, corrección de errores en BOE n. ${ }^{\circ} 229$, de 22 de septiembre) y el Real Decreto 2350/2004, de 23 de diciembre, sobre revalorización de las pensiones del sistema de la Seguridad Social para el ejercicio 2005 (BOE n. ${ }^{\circ}$ 314, de 30 de diciembre).

Respecto a la protección de la salud, deben mencionarse el Real Decreto Ley 9/2004, de 3 de diciembre, por el que se determina el plazo para la ejecución de los procesos previstos en la Ley 16/2001, de 21 de noviembre, por la que se establece un proceso extraordinario de consolidación y provisión de plazas de personal estatutario en las Instituciones Sanitarias de la Seguridad Social de los Servicios de Salud del 
Sistema Nacional de Salud (BOE n. ${ }^{\circ} 292$, de 4 de diciembre), convalidado el 22 de diciembre (BOE n. ${ }^{\circ} 314$, de 30 de diciembre); el Real Decreto 2198/2004, de 25 de noviembre, por el que se determinan los colectivos a los que se dirigen las políticas de cohesión a efectos de su financiación por el Fondo de cohesión sanitaria durante el ejercicio 2004 (BOE n. ${ }^{\circ} 285$, de 26 de noviembre) y el Real Decreto 2402/2004, de 30 de diciembre, por el que se desarrolla el artículo 104 de la Ley 25/1990, de 20 de diciembre, del Medicamento, para las revisiones coyunturales de precios de especialidades farmacéuticas y se adoptan medidas adicionales para la contención del gasto farmacéutico (BOE $n .^{\circ}$ 315, de 31 de diciembre).

En el ámbito autonómico ha de citarse la Ley de la Comunidad de Madrid 7/2004, de 28 de diciembre, de medidas en materia sanitaria (BOCM n. ${ }^{\circ}$ 310, de 30 de diciembre; BOE n. ${ }^{\circ} 42$, de 18 de febrero de 2005).

Sobre el deporte han de mencionarse el Real Decreto 255/2004, de 13 de febrero, por el que se modifica el Real Decreto 1313/1997, de 1 de agosto, por el que se establece la composición y funciones de la Comisión Nacional Antidopaje (BOE n. ${ }^{\circ} 48$, de 25 de febrero) y el Real Decreto $2195 / 2004$, de 25 de noviembre, por el que se regula la estructura orgánica y las funciones del Consejo Superior de Deportes (BOE n. ${ }^{\circ}$ 285, de 26 de noviembre).

En cultura cabe citar el Real Decreto 1652/2004, de 9 de julio, por el que se aprueba el Reglamento que regula la inversión obligatoria para la financiación anticipada de largometrajes y cortometrajes cinematográficos y películas para televisíon, europeos y españoles (BOE n. ${ }^{\circ} 174$, de 20 de julio) y el Real Decreto 1893/2004, de 10 de septiembre, por el que se crea la Comisión Interministerial para la coordinación del uno por cien cultural (BOE n. ${ }^{\circ} 227$, de 20 de septiembre).

En materia medioambiental, se aprobaron el Real Decreto-Ley 2/2004, de 18 de junio, por el que se modifica la Ley 10/2001, de 5 de julio, del Plan Hidrológico Nacional (BOE n. ${ }^{\circ} 148$, de 19 de junio), convalidado el 29 de junio (BOE n. ${ }^{\circ} 160$, de 3 de julio); el Real Decreto-Ley $4 / 2004$, de 2 de julio, por el que se adoptan determinadas medidas relacionadas con los daños ocasionados por el accidente del buque Prestige (BOE n. ${ }^{\circ}$ 160, de 3 de julio), convalidado el 21 de julio (BOE n. ${ }^{\circ} 178$, de 24 de julio); el Real Decreto-Ley 5/2004, de 27 de agosto, por el que se regula el régimen del comercio de derechos de emisión de gases de efecto invernadero (BOE n. ${ }^{\circ} 208$, de 28 de agosto), convalidado el 16 de septiembre (BOE n. ${ }^{\circ} 228$, de 21 de septiembre) y el Real Decreto-Ley $6 / 2004$, de 17 septiembre, por el que se adoptan medidas urgentes para 
reparar los daños causados por los incendios e inundaciones acaecidos en las Comunidades Autónomas de Aragón, Cataluña, Andalucía, Comunidad Foral de Navarra y Comunidad Valenciana (BOE n. ${ }^{\circ} 226$, de 18 de septiembre), convalidado el 30 de septiembre (BOE n. ${ }^{\circ} 242$, de 7 de octubre).

Además, deben citarse el Real Decreto 1866/2004, de 6 de septiembre, por el que se aprueba el Plan Nacional de derechos de emisión 2005-2007 (BOE n. ${ }^{\circ} 216$, de 7 de septiembre); el Real Decreto 1892/2004, de 10 de septiembre, por el que se dictan normas para la ejecución del Convenio Internacional sobre la responsabilidad civil derivada de daños debidos a la contaminación de las aguas del mar por hidrocarburos (BOE n. ${ }^{\circ} 226$, de 18 de septiembre); el Real Decreto 2129/2004, de 29 de octubre, por el que se modifica el Real Decreto 650/1987, de 8 de mayo, por el que se definen los ámbitos territoriales de los organismos de cuenca y de los planes hidrológicos (BOE n. ${ }^{\circ} 268$, de 6 de noviembre); el Real Decreto 2182/2004, de 12 de noviembre, por el que se crea el Centro para la prevención y lucha contra la contaminación marina y del litoral (BOE n. ${ }^{\circ} 276$, de 16 de noviembre) y el Real Decreto 2355/2004, de 23 de diciembre, por el que se regulan la estructura y funciones del Consejo Asesor del Medio Ambiente (BOE n. ${ }^{\circ}$ 12, de 14 de enero de 2005).

En el la legislación autonómica hay que recordar la Ley 5/2004, de 24 de junio, de prevención y lucha contra los incendios forestales en Extremadura (DOE n. ${ }^{\circ} 74$, de 29 de junio; BOE n. ${ }^{\circ} 172$, de 17 de julio); la Ley 4/2004, de 30 de junio, de la Comunidad Valenciana, de ordenación del territorio y protección del paisaje (DOGV n. ${ }^{\circ} 4788$, de 2 de julio; BOE n. ${ }^{\circ} 174$, de 20 de julio); la Ley catalana $4 / 2004$, de 1 de julio, reguladora del proceso de adecuación de las actividades de incidencia ambiental a lo establecido en la Ley 3/1998, de 27 de febrero, de la intervención integral de la Administración Ambiental (DOGC n. ${ }^{\circ} 4167$, de 5 de julio; BOE n. ${ }^{\circ} 233$, de 27 de septiembre); en Aragón, la Ley 8/2004, de 20 de diciembre, de medidas urgentes en materia de medio ambiente (BOA n. ${ }^{\circ} 151$, de 27 de diciembre; $B O E$ n. ${ }^{\circ} 36$, de 11 de febrero de 2005) y, en Galicia, la Ley 15/2004, de 29 de diciembre, de modificación de la Ley $9 / 2002$, de 30 de diciembre, de ordenación urbanística y protección del medio rural de Galicia (DOG n. ${ }^{\circ} 254$, de 31 de diciembre; BOE n. ${ }^{\circ} 29$ de 3 de febrero de 2005)

En lo que respecta a la protección del patrimonio, se aprobaron la Ley $7 / 2004$, de 18 de octubre, de Patrimonio Cultural, Histórico y Artístico de La Rioja (BOLR n. ${ }^{\circ}$ 135, de 23 de octubre; BOE n. ${ }^{\circ} 272$, de 11 de diciembre); la Ley $7 / 2004$, de 19 de octubre, de modificación de la Ley 4/1998, de 11 de junio, del Patrimonio Cultural Valenciano (DOGV n. ${ }^{\circ}$ 
4867, de 21 de octubre; BOE n. ${ }^{\circ} 279$ de 19 de noviembre); la Ley 7/2004, de 22 de diciembre, de modificación de la Ley 6/1991, de 19 de abril, de Archivos y Patrimonio Documental de Castilla y León (BOCL suplemento n. ${ }^{\circ} 3$ al n. ${ }^{\circ} 246$ de 23 de diciembre; BOE n. ${ }^{\circ} 14$, de 17 de enero) y la Ley $8 / 2004$, de 22 de diciembre, de modificación de la Ley 12/2002, de 11 de julio, del Patrimonio Cultural de Castilla y León (BOCL suplemento n. ${ }^{\circ} 3$ al n. ${ }^{\circ} 246$ de 23 de diciembre; BOE n. ${ }^{\circ} 14$, de 17 de enero).

En materia de vivienda se aprobó el Real Decreto 1721/2004, de 23 de julio, por el que se modifica el Real Decreto 1/2002, de 11 de enero, sobre medidas de financiación de actuaciones protegidas en materia de vivienda y suelo del Plan 2002-2005, y se crean nuevas líneas de actuaciones protegidas para fomentar el arrendamiento de viviendas (BOE n. ${ }^{\circ}$ 181, de 28 de julio).

En las Comunidades Autónomas, la Ley Foral 8/2004, de 24 de junio, de protección pública a la vivienda en Navarra (BON n. ${ }^{\circ} 79$, de 2 de julio; BOE n. ${ }^{\circ} 172$, de 17 de julio); en la Comunidad Valenciana, la Ley 3/2004, de 30 de junio, de ordenación y fomento de la calidad de la edificación (DOGV n. ${ }^{\circ} 4788$, de 2 de julio; BOE n. ${ }^{\circ} 174$, de 20 de julio) y la Ley $8 / 2004$, de 20 de octubre, de la vivienda de la Comunidad Valenciana (DOGV n. ${ }^{\circ} 4867$, de 21 de octubre; BOE n. ${ }^{\circ} 281$, de 22 de noviembre); en Asturias, la Ley $2 / 2004$, de 29 de octubre, de medidas urgentes en materia de suelo y vivienda (BOPA $n .{ }^{\circ} 261$, de 10 de noviembre; BOE n. ${ }^{\circ}$ 296, de 9 de diciembre); en Cataluña la Ley 10/2004, de 24 de diciembre, de modificación de la Ley 2/2002, de 14 de marzo, de urbanismo para el fomento de la vivienda asequible, de la sostenibilidad territorial y de la autonomía local (DOGC n. ${ }^{\circ} 4291$, de 30 de diciembre; BOE n. ${ }^{\circ} 40$, de 16 de febrero de 2005) y en la Comunidad de Aragón, la Ley 9/2004, de 20 de diciembre, de reforma de la Ley $24 / 2003$, de 26 de diciembre, de medidas urgentes de política de vivienda protegida (BOA n. ${ }^{\circ} 151$, de 27 de diciembre; BOE n. ${ }^{\circ} 42$, de 18 de febrero de 2005).

En orden a la atención de las personas con discapacidades se aprobaron el Real Decreto 1865/2004, de 6 de septiembre, por el que se regula el Consejo Nacional de la Discapacidad (BOE n. ${ }^{\circ} 216$, de 7 de septiembre de 2004); el Real Decreto 2270/2004, de 3 de diciembre, por el que se modifica el Real Decreto 177/2004, de 30 de enero, por el que se determina la composición, funcionamiento y funciones de la Comisión de protección patrimonial de las personas con discapacidad (BOE n. ${ }^{\circ}$ 303 , de 17 de diciembre) y el Real Decreto 2271/2004, de 3 de diciembre, por el que se regula el acceso al empleo público y la provisión de puestos de trabajo de las personas con discapacidad (BOE n. ${ }^{\circ} 303$, de 17 de diciembre). 
Para la protección de los consumidores y usuarios destaca, entre la normativa aprobada, el Real Decreto 2220/2004, de 26 de noviembre, por el que se modifica la norma general de etiquetado, presentación y publicidad de los productos alimenticios, aprobada por el Real Decreto 1334/1999, de 31 de julio (BOE n. ${ }^{\circ} 286$, de 27 de noviembre); además, cabe recordar la Ley $11 / 2004$, de 19 de noviembre, de inspección de consumo de Galicia (DOG n. ${ }^{\circ} 234$, de 2 de diciembre; BOE n. ${ }^{\circ} 305$, de 20 de diciembre) y la Ley $9 / 2004$, de 24 de diciembre, de creación de la Agencia Catalana del Consumo (DOCA n. ${ }^{\circ} 4291$, de 30 de diciembre; BOE n. ${ }^{\circ} 40$, de 16 de febrero de 2005).

\section{RELACIONES INTERNACIONALES}

En lo que tiene que ver con la actividad normativa derivada de las relaciones internacionales de nuestro país, hay que hacer mención a los siguientes Convenios:

Instrumento de Ratificación del Convenio de Estocolmo sobre contaminantes orgánicos persistentes, hecho en Estocolmo el 22 de mayo de 2001 (BOE n. ${ }^{\circ}$ 151, de 23 de junio de 2004); al Instrumento de Ratificación del Convenio relativo a la expedición de un certificado de vida (número 27 de la CIEC), hecho en París el 10 de septiembre de 1998 (BOE n. ${ }^{\circ}$ 194, de 12 de agosto de 2004); Instrumento de Adhesión al Protocolo de 1997 que enmienda el Convenio internacional para prevenir la contaminación por los buques, 1973, modificado por el Protocolo de 1978 hecho en Londres el 26 de septiembre de 1997 (BOE n. ${ }^{\circ} 251$, de 18 de octubre de 2004); Instrumento de Ratificación del Protocolo de 2003 relativo al Convenio Internacional sobre la constitución de un Fondo Internacional de Indemnización de daños debidos a contaminación por hidrocarburos, 1992, hecho en Londres el 16 de mayo de 2003 (BOE n. ${ }^{\circ} 28$, de 2 de febrero); Instrumento de Ratificación del Protocolo de Kyoto al Convenio Marco de las Naciones Unidas sobre el Cambio Climático, hecho en Kyoto el 11 de diciembre de 1997 (BOE n. ${ }^{\circ} 33$, de 8 de febrero); Instrumento de Ratificación del Convenio Marco de la OMS para el control del tabaco, hecho en Ginebra el 21 de mayo de 2003 (BOE n. ${ }^{\circ}$ 35, de 10 de febrero de 2005) y al Instrumento de Ratificación del Acuerdo entre los Estados parte en el Convenio para el establecimiento de una Agencia Espacial Europea y la Agencia Espacial Europea para la protección y el intercambio de información clasificada, hecho en París el 19 de agosto de 2002 (BOE n. ${ }^{\circ}$ 53, de 3 de marzo de 2005).

Por otra parte, el Estado español, por medio de tres notas verbales de 22 de diciembre, ha denunciado varios Convenios:

el Convenio Internacional para la unificación de ciertas reglas relativas a la limitación de la responsabilidad de los propietarios de buques y 
Protocolo de firma, hecho en Bruselas el 25 de agosto de 1924; el Convenio Internacional relativo a la limitación de la responsabilidad de los propietarios de buques que navegan por alta mar, hecho en Bruselas el 10 de octubre de 1957, y el Protocolo que modifica el Convenio Internacional de 10 de octubre de 1957, relativo a la limitación de la responsabilidad de propietarios de buques que navegan por el mar, hecho en Bruselas el 21 de diciembre de 1979. Estas Denuncias surtirán efecto para España el 4 de enero de 2006 (BOE n. ${ }^{\circ}$ 52, de 2 de marzo de 2005).

En el ámbito jurisprudencial es de reseñar que el Tribunal Europeo de Derechos Humanos dictó a lo largo del año 2004 cinco condenas contra España en los siguientes asuntos: en el caso Quiles González contra España (27 de abril), el Tribunal apreció vulneración del artículo 6.1 del Convenio Europeo de Derechos Humanos por la duración excesiva de un procedimiento ante la jurisdicción laboral reclamando una pensión; en el asunto Martínez Sala y otros contra España (2 de noviembre), el Tribunal apreció una lesión del artículo 3 del Convenio debido a la ausencia de investigación profunda sobre las denuncias de malos tratos presentadas por los demandantes; en el caso Sáez Maeso contra España (9 de noviembre), el Tribunal condenó a España por violación del artículo 6.1 al entender que la interpretación excesivamente rigurosa de un requisito formal había privado al demandante de su derecho de acceso al recurso de casación cuando tal derecho había sido reconocido por el propio Tribunal Supremo con anterioridad; en el asunto Alberto Sánchez contra España (16 de noviembre), el Tribunal estimó que había habido una vulneración del artículo 6.1 del Convenio Europeo de Derechos Humanos, dado que una duración global de cinco años, cuatro meses y trece días para resolver un incidente de jurisdicción no es un retraso razonable. Finalmente, en el asunto Moreno Gómez contra España (16 de noviembre), el Tribunal consideró que se había vulnerado el artículo 8 del Convenio Europeo de Derechos Humanos, puesto que una entidad local había permitido el incumplimiento reiterado de su propia normativa en materia de contaminación acústica nocturna, lo que provocó una lesión grave del derecho a la inviolabilidad del domicilio.

Por su parte, en la reunión de Ginebra, del 18 de octubre al 5 de noviembre, el Comité de Derechos Humanos de la ONU aprobó un Dictamen en el que considera vulnerado por España el derecho a la doble instancia penal establecido en el Pacto Internacional de Derechos Civiles y Políticos, por entender que el recurso de casación ante el Tribunal Supremo no cubre esas exigencias al no permitise la revisión de las pruebas. 